\title{
BMP-9 interferes with liver regeneration and promotes liver fibrosis
}

\author{
Katja Breitkopf-Heinlein, ${ }^{1}$ Christoph Meyer, ${ }^{1}$ Courtney König, ${ }^{2}$ Haristi Gaitantzi, ${ }^{1}$ \\ Annalisa Addante, ${ }^{3}$ Maria Thomas, ${ }^{4}$ Eliza Wiercinska, ${ }^{5}$ Chen Cai, $^{1}$ Qi Li, ${ }^{1,6}$ \\ Fengqi Wan, ${ }^{1}$ Claus Hellerbrand, ${ }^{7}$ Nektarios A Valous, ${ }^{8}$ Maximilian J Hahnel, ${ }^{9}$ \\ Christian Ehlting, ${ }^{9}$ Johannes G Bode, ${ }^{9}$ Stephanie Mueller-Bohl, ${ }^{10}$ Ursula Klingmüller, ${ }^{10}$ \\ Jutta Altenöder, ${ }^{1}$ Iryna Ilkavets, ${ }^{1}$ Marie-José Goumans, ${ }^{11}$ Lukas J A C Hawinkels, ${ }^{11}$ \\ Se-Jin Lee, ${ }^{12}$ Matthias Wieland, ${ }^{2}$ Carolin Mogler, ${ }^{13}$ Matthias P Ebert, ${ }^{1}$ \\ Blanca Herrera, ${ }^{3}$ Hellmut G Augustin, ${ }^{2,14,15}$ Aránzazu Sánchez, ${ }^{3}$ Steven Dooley, ${ }^{1}$ \\ Peter ten Dijke ${ }^{11}$
}

- Additional material is published online only. To view please visit the journal online (http://dx.doi.org/10.1136/ gutjnl-2016-313314).

For numbered affiliations see end of article.

Correspondence to Dr Katja Breitkopf-Heinlein, Department of Medicine II Medical Faculty Mannheim, Heidelberg University, TheodorKutzer-Ufer 1-3, Mannheim D-68167, Germany; katja. breitkopf@medma.uniheidelberg.de

CM, CK, HG and AA shared second authorship.

AS, SD, PtD shared senior authorship.

Received 28 October 2016 Revised 22 February 2017 Accepted 2 March 2017 Published Online First 23 March 2017
CrossMark

To cite: Breitkopf-Heinlein $\mathrm{K}$ Meyer C, König C, et al. Gut 2017;66:939-954.

\section{ABSTRACT}

Objective Bone morphogenetic protein (BMP)- 9 , a member of the transforming growth factor- $\beta$ family of cytokines, is constitutively produced in the liver. Systemic levels act on many organs and tissues including bone and endothelium, but little is known about its hepatic functions in health and disease.

Design Levels of BMP-9 and its receptors were analysed in primary liver cells. Direct effects of BMP-9 on hepatic stellate cells (HSCs) and hepatocytes were studied in vitro, and the role of BMP-9 was examined in acute and chronic liver injury models in mice.

Results Quiescent and activated HSCs were identified as major BMP-9 producing liver cell type. BMP-9 stimulation of cultured hepatocytes inhibited proliferation, epithelial to mesenchymal transition and preserved expression of important metabolic enzymes such as cytochrome P450. Acute liver injury caused by partial hepatectomy or single injections of carbon tetrachloride $\left(\mathrm{CCl}_{4}\right)$ or lipopolysaccharide (LPS) into mice resulted in transient downregulation of hepatic BMP-9 mRNA expression. Correspondingly, LPS stimulation led to downregulation of BMP-9 expression in cultured HSCs. Application of BMP-9 after partial hepatectomy significantly enhanced liver damage and disturbed the proliferative response. Chronic liver damage in BMP-9deficient mice or in mice adenovirally overexpressing the selective BMP-9 antagonist activin receptor-like kinase 1Fc resulted in reduced deposition of collagen and subsequent fibrosis

Conclusions Constitutive expression of low levels of BMP-9 stabilises hepatocyte function in the healthy liver. Upon HSC activation, endogenous BMP-9 levels increase in vitro and in vivo and high levels of BMP-9 cause enhanced damage upon acute or chronic injury.

\section{INTRODUCTION}

Bone morphogenetic proteins (BMPs) belong to the transforming growth factor (TGF)- $\beta$ family of cytokines. ${ }^{1}$ Currently, about 20 different BMPs have been identified and are grouped into subfamilies, according to similarities in their amino acid

\section{Significance of this study}

What is already known on this subject?

- Bone morphogenetic protein (BMP)-9 is a member of the transforming growth factor (TGF)- $\beta$ family of cytokines, is produced by the liver and is constantly secreted into the blood stream.

- BMP-9 acts antiproliferative and stabilising on mature (healthy) vessels but can promote angiogenesis in different tumours.

- BMP-9 induces epithelial to mesenchymal transition of hepatocellular carcinoma cells and its protein levels correlate with aggressiveness of hepatocellular carcinoma in patient samples.

- BMP-9 is a high-affinity ligand for the type I receptor activin receptor-like kinase 1.

What are the new findings?

- Hepatic stellate cells (HSCs) are the cellular source for BMP-9, and HSCs express and secrete increasing amounts during their fibrogenic activation.

- BMP-9 acts antiproliferative and stabilising on primary (healthy) hepatocytes including maintenance of cell polarisation and expression of metabolic enzymes like cytochrome P450 oxidases.

- Low levels of BMP-9 promote hepatic wound healing and regeneration in mouse models of acute liver damage.

- Absence or inhibition of BMP-9 during chronic liver damage (repeated injections of $\mathrm{CCl}_{4}$ to mice) significantly ameliorates fibrogenesis.

How might it impact on clinical practice in the foreseeable future?

- Transient inhibition of BMP-9 by itself or in combination with existing therapy strategies could significantly improve the hepatic wound healing and regeneration capacity upon acute as well as chronic liver injury. 
sequences. BMPs are secreted glycoproteins involved in a large array of biological activities including proliferation, differentiation and survival, therefore playing important roles in embryology, tissue regeneration and cancer. ${ }^{1-4}$ BMPs initiate signalling from the cell surface by binding to two different types of serine/ threonine kinase receptors (I and II). Formation of the active ligand-receptor complex induces signal transduction pathways through phosphorylation of small mothers against decapentaplegic (SMAD) proteins, and through SMAD-independent pathways via mitogen-activated protein kinases (extracellular signalregulated kinase, p38 mitogen-activated protein kinases, c-Jun $\mathrm{N}$-terminal kinase). ${ }^{5}{ }^{6}$ BMPs can act in an autocrine or paracrine manner and the outcome is highly context dependent. ${ }^{7-10}$

BMP-9 and BMP-10 represent the most recently discovered members of the BMP family. Whereas most BMPs signal via the type I receptors activin receptor-like kinase (ALK)2, ALK-3 or ALK-6, BMP-9 and BMP-10 show highest affinity for ALK1. ${ }^{11} 12$ Yet, cells still respond to BMP-9 in the absence of ALK1 by signalling through ALK2. ${ }^{11} 13$ BIAcore experiments have revealed high affinity of BMP-9 to ALK1 and ActRIIB and lower affinity binding to ALK2 and the other type II receptors BMPRII and ActRIIA. ${ }^{14}{ }^{15}$ Whereas BMP-10 seems to be primarily expressed in the developing heart, ${ }^{16}$ BMP-9 is preferentially expressed in the liver. ${ }^{17-19}$ Constitutive low-level expression results in detectable levels of circulating BMP-9 in healthy individuals. ${ }^{17}{ }^{20}$ Features distinguishing BMP-9 from other BMPs are among others that it does not bind to the BMP-co-receptor hemojuvelin or the soluble BMP-antagonist $\operatorname{noggin}^{21} 22$ and that BMP-9 complexed to its prodomains is biologically active. ${ }^{23}$ It seems that upon contact with its receptors BMP-9 always turns into an active conformation, even if it is still complexed to its prodomains. ${ }^{24}$ Interestingly, BMP-9 and BMP-10 can directly bind to ALK1 and ActRIIB with similar high affinity. ${ }^{14}$ ALK1-Fc, in which the extracellular domain of ALK1 is fused to the Fc part of immunoglobulin, serves as an efficient and specific BMP-9 and BMP-10 ligand trap. ${ }^{25}$ We have recently shown that BMP-9 acts protumorigenic on liver cancer cells. ${ }^{6}{ }^{26}$ However, possible functions of BMP-9 on primary non-transformed hepatocytes (HCs) have not been investigated in much detail. We therefore aimed at better characterising functions of BMP-9 in healthy and diseased liver. The data demonstrate that although physiological levels of BMP-9 seem to stabilise the epithelial phenotype of the parenchyma, high levels of BMP-9 are counteracting with cellular programmes of wound healing and/or regeneration; therefore, BMP-9 levels drop transiently during acute damage. Correspondingly, we found that hepatic wound healing in vivo is more efficient when BMP-9 is inhibited (by ALK1-Fc) or absent (in BMP-9-deficient animals). Our data demonstrate that BMP-9 represents an important factor for liver homeostasis and suggest that transient inhibition of BMP-9 might be a new option to improve hepatic wound healing and regeneration processes in patients.

\section{MATERIALS AND METHODS Adenoviruses}

AdLacZ and AdId1 have been used as described previously. ${ }^{27}$ For construction of AdBMP-9, AdFc and AdALK1-Fc adenoviral constructs, human coding sequences were recombined by a clonase reaction in pAD/DEST (Invitrogen), and adenoviruses were generated according to the manufacturer's protocol.

\section{Cytokines}

Recombinant human BMP-9, BMP-2, BMP-6 and mouse hepatocyte growth factor (HGF) were from R\&D Systems
(Wiesbaden-Nordenstadt, Germany) and recombinant human TGF- $\beta 1$ and platelet derived growth factor (PDGF)-B were from Peprotech (Rocky Hill, USA).

\section{Antibodies}

Western blot: a monoclonal rabbit anti-Smad3 (phospho S423 +S425) antibody (EP823Y) (ab52903) was used to detect phospho-Smad1/3 (Abcam). A polyclonal rabbit antibody (detecting phosphorylation at Ser465/467) was used to detect phospho-Smad2 (Cell Signalling Technology). Rabbit polyclonal antibody for $\alpha$ smooth muscle actin ( $\alpha$ SMA) was from Abcam (ab7817) and a polyclonal rabbit antibody for glyceraldehyde 3phosphate dehydrogenease (GAPDH) and a monoclonal mouse anti-actin for $\beta$-actin were obtained from Santa Cruz.

Immunohistochemistry: A Ki-67 rat anti-mouse antibody was obtained from Dako. A monoclonal mouse against $\alpha \mathrm{SMA}$ (M0851) was from DAKO, and a monoclonal rabbit anti-cleaved caspase-3 (Asp175; 5A1E) was from Cell Signalling Technology.

\section{Mice}

All experimental animal protocols were performed in accordance with European Community policies, and approved by local committees. BMP-9-deficient mice were generated as previously described $^{12}$ and were maintained on a C57BL/6 background.

\section{Cell isolation and culture}

Mouse HCs were isolated from male C57BL/6 mice (813 weeks old) by collagenase perfusion as described. ${ }^{28}$ Mean viability of HCs was approximately 95\%. Primary HCs were cultured in three kinds of media: medium 1: Williams' medium E supplemented with $10 \%$ fetal calf serum (FCS), $2 \mathrm{mM}$ L-glutamine, $1 \%$ penicillin/streptomycin and $100 \mathrm{nM}$ dexamethasone. Medium 2: medium 1 without FCS. Medium 3: Williams' medium E supplemented only with $2 \mathrm{mM}$ L-glutamine and $1 \%$ penicillin/streptomycin. Freshly isolated HCs were plated on collagen-coated $3.5 \mathrm{~cm}$ plates at a density of $4 \times 10^{5}$ cells/dish in medium 1 and incubated in $5 \% \mathrm{CO}_{2}$ at $37^{\circ} \mathrm{C}$ for 4 hours. Medium 1 was replaced with medium 2 for serum starvation and cell cycle synchronisation. On the second day, medium 2 was changed to medium 3.

Hepatic stellate cells (HSCs) were isolated from female Balb/c mice by pronase/collagenase digestion followed by single-step density gradient centrifugation with Nycodenz (Nyegaard Co. AS, Oslo, Norway), essentially as previously described for rats. ${ }^{27}$ Briefly, Balb/c mice (weighing ca. $20 \mathrm{~g}$ ) were anesthetised and the abdominal cavity was opened under sterile conditions. The liver was perfused via the portal vein with Hanks buffered balanced salt solution without $\mathrm{Ca}^{2+}$ and $\mathrm{Mg}^{2+}$. After complete perfusion, the liver was transferred to a funnel and perfused with pronase for $4 \mathrm{~min}$, followed by perfusion with collagenase for $7 \mathrm{~min}$. The liver was then dissociated and the cell suspension was submitted to density gradient centrifugation with Nycodenz and washed several times. Cells were resuspended with Dulbecco's modified Eagle's medium (DMEM) $+10 \%$ FCS. The mean purity as determined by ultra violet (UV) autofluorescence was $\geq 95 \%$. The cells were then cultured in DMEM, supplemented with $4 \mathrm{mM}$ L-glutamine, 10\% FCS and penicillin (100 IU/ $\mathrm{mL}) /$ streptomycin $(100 \mu \mathrm{g} / \mathrm{mL})$. The first change of medium was performed 1-2 hours after seeding to remove any non-adherent cells and debris. For stimulation experiments with HSCs, the concentration of FCS was reduced to $0.5 \%$ overnight.

LX-2 is a human HSC line, which was cultured in DMEM supplemented with $2 \%$ FCS, $4 \mathrm{mM} \mathrm{L}$-glutamine and penicillin $(100 \mathrm{IU} / \mathrm{mL}) /$ streptomycin $(100 \mu \mathrm{g} / \mathrm{mL})$. 


\section{Scratch assay (LX-2)}

LX-2 cells were cultured in 12-well plates until confluency to determine their wound-closure capacity. The cells were cultured in medium without FCS overnight. Using a pipet tip, the monolayer was scratched carefully, followed by stimulation with recombinant BMP-9 (at concentrations of 5, 10 and $50 \mathrm{ng} / \mathrm{mL}$ ). Images were taken immediately ( $\mathrm{t}=0$ hour) and after 24 hours (seven images per scratch). The remaining diameter of the untreated condition was set as 1 and treatment conditions were expressed as 'fold of untreated'.

\section{Simultaneous isolation of four liver cell types from mouse liver}

After isolation of primary HCs and HSCs (protocols as described above) from male $\mathrm{C} 57 \mathrm{~B} / 6$ mice, the remaining cell fraction was further processed for isolation of liver sinusoidal endothelial cells (LSECs) and Kupffer cells (KCs) using magnetic microbeads from Miltenyi (CD146 microbeads for LSEC and CD11b for KC) as described earlier. ${ }^{29}$

\section{Human primary HSC isolation and migration assay}

Primary human HSCs were isolated and cultured as described. ${ }^{30}$ In vitro activation of HSCs was achieved by cell culture on uncoated tissue culture dishes.

Migratory activity of HSCs was quantified using Cultrex 96 Well Cell Migration assay (Trevigen, Gaithersburg, USA) as described. ${ }^{31}$ Briefly, HSCs were stimulated or not with BMP-9 for 24 hours. Subsequently, cells were trypsinised and seeded in DMEM without FCS into the upper compartment of the provided 96-well micropore plate $\left(10 \times 10^{3}\right.$ cells/well). The lower compartment was filled with DMEM supplemented with $10 \%$ FCS to assess directed migration. After incubation at $37^{\circ} \mathrm{C}$ for 5 hours, cell migration was quantified by fluorimetry with an EMax Microplate Reader (MWG Biotech, Ebersberg, Germany).

\section{Immunoblot analyses}

Total cell protein was harvested on ice with radioimmunoprecipitation assay lysis buffer ( $1 \times$ Tris-buffer, $1 \%$ Nonidet P40, $0.5 \%$ sodium deoxycholate and $0.1 \%$ sodium dodecylsulfate) in the presence of freshly added protease and phosphatase inhibitors (Roche, Mannheim, Germany). Protein concentration was measured with a Bio-Rad protein assay (Biorad, München, Germany). Proteins were separated by $4 \%-12 \%$ sodium dodecyl sulfate/polyacrylamide gel electrophoresis (NuPAGE, Invitrogen) and transferred to nitrocellulose membranes (Pierce, Rockford, Illinois, USA). Incubation with the primary antibodies occurred at $4^{\circ} \mathrm{C}$ overnight. Horseradish peroxidase-linked secondary antibodies (Santa Cruz, Heidelberg, Germany) were used. The membranes were developed with Supersignal Ultra (Pierce, Hamburg, Germany), and chemiluminescence was detected digitally with a Fujifilm LAS 1000 image detection system.

\section{HC proliferation measurements}

Since primary HCs in monolayer culture display only very low basal proliferative activity, a more sensitive assay to detect changes in cellular DNA content was performed as described by Huard et al. ${ }^{32}$ Briefly, freshly isolated HCs were plated on collagen-coated $3.5 \mathrm{~cm}$ plates at a density of $1.25 \times 10^{5}$ cells/ dish as described above. On the second day, medium 2 was changed to medium 3 and the cells were stimulated with HGF $(40 \mathrm{ng} / \mathrm{mL})$, BMP-9 $(5-50 \mathrm{ng} / \mathrm{mL})$ or a combination of both for 48 hours. In each experiment, cells derived from a single animal were used, and treatments were performed in triplicates. Cells were washed twice with phosphate buffered saline (PBS) and were frozen at $-20^{\circ} \mathrm{C}$. To assay DNA content, plates were incubated with $2 \mathrm{~mL} /$ well of Sybr Green I working solution (Sybr Green I $10000 \times$ (Invitrogen, Darmstadt, Germany), diluted 1:2500 in PBS, supplemented with $0.1 \%(\mathrm{v} / \mathrm{v})$ Triton $\times 100$ for 1 hour in the dark. Fluorescence intensity was measured using an Infinite F200 Pro plate reader (Tecan, Männedorf, Switzerland) with $\lambda_{\text {excitation }}=485 \mathrm{~nm}$ and $\lambda_{\text {emission }}=535 \mathrm{~nm}$. Four experiments were performed for statistical analysis, and individual datasets were scaled to the mean of the respective experiment.

\section{HSC proliferation experiments}

Human HSCs (between passage 3 and 5 isolated from four different donors) or LX-2 cells were cultured with or without BMP-9 $(5 \mathrm{ng} / \mathrm{mL})$ for 72 hours, then the cells were dislodged by trypsin and were counted.

\section{Determination of RNA expression}

Total RNA was isolated from cells or tissue and equal amounts were reverse transcribed into cDNA. High-throughput quantitative real-time PCR (RT-PCR) analysis: total RNA was isolated from the tissue using RNeasy Mini Kit including on column genomic DNA digestion with RNase-free DNase Set (Qiagen, Hilden, Germany) and from cultured cells using high pure RNA isolation kits from Roche (Mannheim, Germany). RNA was reverse transcribed to cDNA using avian myeloblastosis virus reverse transcriptase (Roche). For quantitative RT-PCR, we used either the Fluidigm's Biomark high-throughput quantitative (q) PCR chip platform (Fluidigm, San Francisco, California, USA) with predesigned gene expression assays from Applied Biosystems according to the manufacturer's instructions ${ }^{33} 34$ or regular Sybr Green-based RT-PCR was performed (40 PCR cycles on an ABI Prism 7900HT System). Primers used for RT-PCR are given in tables 1 and 2. mRNA expression levels were normalised to suitable housekeeping genes as indicated in the figure legends.

\section{Sirius red staining and quantification}

Sirius red staining was performed for 1 hour $(0.1 \mathrm{~g}$ Sirius red/ $100 \mathrm{~mL}$ picric acid; Sigma-Aldrich) as previously described. ${ }^{35}$ Samples were imaged using an Aperio slide scanner followed by whole slide image analysis with Aperio ImageScope. For quantification of positive areas, the Positive Pixel Count V.9.1 algorithm was used (pixel area $/ \mathrm{mm}^{2} /-2.44827 \times 10^{-7}$ ). Three biological replicas per condition were used to quantify the Sirius red-positive area. Data are displayed as number of pixels in positive area versus number of pixels in total area (=positivity).

\section{BMP-9 ELISA}

An ELISA for mouse BMP-9 was developed. Nunc maxisorp plates (Nunc, Denmark) were coated with mouse anti-human BMP-9 antibodies $(1 \mu \mathrm{g} / \mathrm{mL}$ in PBS, R\&D Systems, Abington, $\mathrm{UK}) \mathrm{O} / \mathrm{N}$ at room temperature (RT). Between all steps, plates were washed with PBS containing 0.05\% Tween-20 (Merck). Plates were blocked with 5\% Tween-20, 0.05\% sodium azide in PBS for 1 hour, followed by incubation with plasma samples $(50 \mu \mathrm{L}$ diluted with $1 \%$ bovine serum albumin (BSA) (PAA, Germany)/PBS) or a standard (recombinant mouse BMP-9, R\&D Systems) for 2 hours at RT. Detection was performed with biotinylated goat anti-human BMP-9 antibodies $(0.2 \mu \mathrm{g} / \mathrm{mL}$ in 1\% BSA/PBS 2 hours, RT), streptavidin-horse radish peroxidase and a substrate reagent pack (all R\&D Systems) as described previously. $^{36} 37$ 
Table 1 Sequences of the mouse primers used for real-time PCR (always in $5^{\prime} \geq 3^{\prime}$ orientation)

\begin{tabular}{|c|c|c|}
\hline Target gene & Forward sequence & Reverse sequence \\
\hline Acta2 ( $\alpha S M A)$ & GCTGAAGTATCCGATAGAACACG & GGTCTCAAACATAATCTGGGTCA \\
\hline ActRIIB & AGGCAACTTCTGCAACGAG & CTTCCGATGACGATACATCCAG \\
\hline Albumin & GAAGACCCCAGTGAGTGAGC & CAGTCGAGAAGCAGGTGTCC \\
\hline ALK1 & GGCCTTTTGATGCTGTCG & ATGACCCCTGGCAGAATG \\
\hline ALK2 & GTGGAAGATTACAAGCCACCA & GGGTCTGAGAACCATCTGTTAGG \\
\hline BMP-9 & CAGAACTGGGAACAAGCATCC & GCCGCTGAGGTTTAGGCTG \\
\hline$\beta$-Actin & GGCTGTATTCCCCTCCATCG & CCAGTTGGTAACAATGCCATGT \\
\hline$\beta 2$ Microglobulin & TTCTGGTGCTTGTCTCACTGA & CAGTATGTTCGGCTTCCCATTC \\
\hline$C D 11 b$ & AAACCACAGTCCCGCAGAGA & CGTGTTCACCAGCTGGCTTA \\
\hline Col1a1 & TCAGAGGCGAAGGCAACAGT & CCCCAAGTTCCGGTGTGA \\
\hline Desmin & TACACCTGCGAGATTGATGC & ACATCCAAGGCCATCTTCAC \\
\hline E-cadherin & ACTGTGAAGGGACGGTCAAC & GGAGCAGCAGGATCAGAATC \\
\hline Endoglin & СCCTCTGCCCATTACCCTG & GTAAACGTCACCTCACCCCTT \\
\hline Fibronectin & ATGTGGACCCCTCCTGATAGT & GCCCAGTGATTTCAGCAAAGG \\
\hline Gusb & AAAATGGAGTGCGTGTTGGGTCG & CCACAGTCCGTCCAGCGCCTT \\
\hline Hamp1 & ATACCAATGCAGAAGAGAAGG & AACAGATACCACACTGGGAA \\
\hline$H n f 4 \alpha$ & GGCATGGATATGGCCGACTAC & TTCAGATGGGGACGTGTCATT \\
\hline Id1 & CTTCAGGAGGCAAGAGGAAA & САAАCCCTCTACCCACTGGA \\
\hline Lyve-1 & CAGCACACTAGCCTGGTGTTA & CGCCCATGATTCTGCATGTAGA \\
\hline Mki67 & ATCATTGACCGCTCCTTTAGGT & GCTCGCCTTGATGGTTCCT \\
\hline Pcna & TACAGCTTACTCTGCGCTCC & TGTCTGCATTATCTTCAGCCCT \\
\hline Pdgfb & CATCCGCTCCTTTGATGATCTT & GTGCTCGGGTCATGTTCAAGT \\
\hline Peptidy/prolyl isomerase $A$ & CAAATGCTGGACCAAACACAAACG & GTTCATGCCTTCTTTCACCTTCCC \\
\hline Ppary & AGCTGTCATTATTCTCAGTGGAGAC & CTGTCTTCTTGATCACATGCAGTAG \\
\hline Smad6 & AGCATTTTCTACGACCTACCTCA & CCTTGATGGAGTAACCCGGTG \\
\hline Snai1 & CAACTATAGCGAGCTGCAGGA & ACTTGGGGTACCAGGAGAGAGT \\
\hline$T G F-\beta 1$ & GGTCACCCGCGTGCTAATG & CAGAAGTTGGCATGGTAGCC \\
\hline$C T G F$ & GGGCCTCTTCTGCGATTTC & ATCCAGGCAAGTGCATTGGTA \\
\hline VEGF-A & AACGATGAAGCCCTGGAGTG & AACAAGGCTCACAGTGAACG \\
\hline Vimentin & CGGCTGCGAGAGAAATTGC & CCACTTTCCGTTCAAGGTCAAG \\
\hline
\end{tabular}

ALK, activin receptor-like kinase; $\alpha$ SMA, $\alpha$ smooth muscle actin; BMP, bone morphogenetic protein; CTGF, connective tissue growth factor; Pcna, proliferation cell nuclear antigen; Smad, small mothers against decapentaplegic; TGF, transforming growth factor; VEGF, vascular endothelial growth factor.

\section{$\mathrm{CCl}_{4}$ animal experiments}

Male Balb/c mice (five animals per group) weighing 20-25 g and 8 weeks old were used for the $\mathrm{CCl}_{4}$ time-course experiments. Liver injury was induced by intraperitoneal injection of $1.6 \mathrm{~g} / \mathrm{kg}$ body weight of $\mathrm{CCl}_{4}\left(\mathrm{CCl}_{4}\right.$ was mixed 1:8 with mineral oil). Male $\mathrm{C} 57 \mathrm{BL} / 6$ mice were used for chronic liver injury, which received three intraperitoneal injections of $\mathrm{CCl}_{4}$ per week for 4 weeks. At day 7 (after 1 week and three $\mathrm{CCl}_{4}$ injections), animals received an intravenous injection of $10^{9}$ viral particles (AdFc or AdALK1-Fc) in $50 \mu \mathrm{L}$ saline. Animals were sacrificed after 4 weeks and liver samples were snap frozen in liquid nitrogen or fixed in $4 \%$ buffered formalin for histology. The same protocol was performed for experiments with wild-type versus BMP-9 knock out $(\mathrm{KO})$ mice, but with only two injections per week for a period of 8 weeks in total.

Table 2 Sequences of the human primers used for real-time PCR (always in $5^{\prime} \geq 3^{\prime}$ orientation)

\begin{tabular}{lll}
\hline Target gene & Forward sequence & Reverse sequence \\
\hline 32 Microglobulin & GACTTGTCTTTCAGCAAGGA & ACAAAGTCACATGGTTCACA \\
Col1a1 & GTGCGATGACGTGATCTGTGA & CGGTGGTTCTTGGTCGGT \\
\hline
\end{tabular}

\section{Acute injury animal experiments (LPS and $\mathrm{CCl}_{4}$ )}

Male C57BL/6 mice were used for acute liver injury studies. Mice received one intraperitoneal injection of either lipopolysaccharide (LPS) (1 $\mu \mathrm{g} / \mathrm{g}$ body weight), $\mathrm{CCl}_{4}(1.6 \mathrm{~g} / \mathrm{kg}$ body weight) or PBS (control). In addition, one group of animals received recombinant BMP-9 (100 ng per mouse) alone every 24 hours or in combination with the $\mathrm{LPS} / \mathrm{CCl}_{4}$ injections. Mice were sacrificed at the times indicated in the figures, and blood and livers were collected.

\section{Partial hepatectomy}

Two-third partial hepatectomy (PH) experiments with mice were carried out as described. ${ }^{38}$ Half of the mice additionally received recombinant BMP-9 every 24 hours as described above. Mice were sacrificed at the times indicated in the figures, and blood and livers were collected.

\section{Immunohistochemistry}

Formalin-fixed, paraffin-embedded tissue sections were dewaxed and rehydrated through a graded ethanol series and incubated at $60^{\circ} \mathrm{C}$ for $60 \mathrm{~min}$. Antigen unmasking was performed using a citrate buffer $(0.01 \mathrm{M}$ sodium citrate $\mathrm{pH} 6)$ in a water bath at $95^{\circ} \mathrm{C}$ for $20 \mathrm{~min}$ followed by cooling in distilled water. Tissues were covered with some drops of 'Dual Endogenous Enzyme Block' in a humid atmosphere for $15 \mathrm{~min}$. After sections were washed with PBS, they were incubated with the diluted first 
antibody at $4^{\circ} \mathrm{C}$ overnight. The corresponding secondary antibodies were added for 1 hour at RT. Sections were covered with $200 \mu \mathrm{L}$ 3,3'-diaminobenzidine (DAB) substrate. Colour development was monitored under the microscope and the reaction was stopped by immersing the sections in distilled water for $5 \mathrm{~min}$. Sections were counterstained in Mayershaemalaun solution for several seconds and rinsed with water, followed by dehydration through ascending ethanol. Clearing was performed in xylene, and sections were mounted with malin oil.

\section{Patient samples}

Frozen human liver fibrosis samples were provided by the tissue bank of the National Center for Tumor Diseases (NCT, Heidelberg, Germany) in accordance with the regulations of the tissue bank and the approval of the ethics committee of Heidelberg University (Ethikvotes \# 206/207, year: 2005).

\section{Immunohistochemical stainings on human cryosections}

Immunohistochemical stains were performed on an automated immunostainer with an iVIEW DAB detection kit (Ventana/ Roche, Tucson, USA) using primary Bmp-9 antibody (1:500, Bio rad) and counterstained with haematoxylin. All slides were evaluated by at least one board certificated surgical pathologist.

\section{Statistics}

Two-sided, unpaired Student's t-test was used to identify significant differences between groups. Classification of significances was determined as follows: $\mathrm{p}<0.05=* ; \quad \mathrm{p}<0.01=* *$; $\mathrm{p}<0.001=* * *$

\section{RESULTS}

\section{HSCs are source and target of BMP-9 in mouse liver}

To molecularly dissect hepatic functions of BMP-9, we first analysed which cell type of the healthy liver expresses the highest levels of BMP-9 mRNA. Towards this end, we isolated four different liver cell types (HC, HSC, LSEC and KC) simultaneously from livers of healthy male mice and directly lysed the cells for RNA purification. Successful enrichment of individual cell types was verified by analyses of expression levels of specific cell-type markers (see online supplementary figure S1). HSCs express highest levels of BMP-9 mRNA (figure 1A). Analysis of BMP-9 receptor expression revealed a heterogeneous expression pattern with each cell type expressing at least one of the two highaffinity receptors: ALK1 or ActRIIB. HSCs and LSECs also expressed similar levels of $A L K 2$, an alternative type I receptor for BMP-9 with lower affinity, as well as endoglin, a co-receptor for BMP-9-signalling (see online supplementary figure S2).

Cultured HSCs are known to spontaneously activate and differentiate into myofibroblasts. ${ }^{39}$ We therefore analysed BMP-9 expression dynamics (RNA and secreted protein) during in vitro activation. Both, mRNA expression and protein secretion of BMP-9 significantly increased in culture and maintained at elevated levels at least for 1 week (figure 1B, C). Furthermore, BMP-9 directly enhanced the wound-closure potential (determined by scratch assay) of the human HSC cell line, LX-2 (figure 1D) and stimulated migration of cultured primary human HSCs (figure 1E). While BMP-9 did enhance proliferation of cultured HSCs (LX-2 as well as primary human HSCs; figure $1 \mathrm{~F}, \mathrm{G}$ ), it had no modulatory effect on the expression of markers associated with the in vitro activation process (figure 1 $\mathrm{H}, \mathrm{I})$. Stimulation with TGF- $\beta$ was used as positive control in these experiments and led to statistically significant changes as expected (upregulation of Col1a1, fibronectin and Pdgfb and downregulation of Ppar $)$. Consistently, culturing primary mouse HSCs in the presence of BMP-9 neutralising ALK1-Fc did not change expression of activation markers, indicating that the cells activate in vitro even without BMP-9 (figure $1 \mathrm{H}$ ).

\section{BMP-9 stabilises epithelial properties of primary HCs}

BMP-9 has been described as a vascular quiescence factor, stabilising the differentiated phenotype of mature endothelial cells. ${ }^{20}$ Primary HCs and hepatoma cell lines are responsive to BMP-9. ${ }^{18} 26$ Primary mouse HCs stimulated in culture with recombinant BMP-9 displayed upregulation of typical BMP-target genes including Id1, hepcidin (hamp1) or Smad6 (figure 2A). BMP-9 inhibited baseline as well as HGF-induced $\mathrm{HC}$ proliferation (figure 2B). Primary HCs cultured as monolayer rapidly lose their epithelial phenotype and acquire mesenchymal properties (epithelial to mesenchymal transition $(\mathrm{EMT})^{40}{ }^{41}$ ). As shown in figure 2C, BMP-9 dose dependently reversed the culture-provoked upregulation of mesenchymal markers like collagen I and fibronectin, as well as downregulation of the epithelial marker E-cadherin. In addition, TGF- $\beta$-mediated induction of the EMT transcription factor Snail $^{42}$ was inhibited by BMP-9 (see online supplementary figure S3). Similarly, BMP-9 enhanced RNA expression of 23 out of 37 tested enzymes and other proteins involved in metabolic activities of HCs (figure 2D). To further investigate the role of BMP-9 in stabilising the HCs' epithelial phenotype, we isolated primary HCs from the livers of BMP-9 KO mice and measured the expression levels of three mesenchymal and three epithelial marker genes. The result shown in figure $2 \mathrm{E}$ demonstrates that without BMP-9 HCs express significantly higher levels of mesenchymal and lower levels of epithelial markers, compared with cells isolated from wild-type livers.

\section{BMP-9 expression is transiently reduced under conditions of acute liver damage}

To assess whether BMP-9 levels might change under conditions of liver damage in vivo, hepatic BMP-9 mRNA expression levels were determined in three different animal models of acute liver damage: single injections of $\mathrm{CCl}_{4}$ or LPS and liver regeneration upon removal of $2 / 3$ of the liver $(\mathrm{PH})$. There was a transient downregulation of BMP-9 expression shortly after onset of damage in all three models (figure $3 \mathrm{~A}-\mathrm{C}$ ). At later time points, BMP-9 expression was elevated on LPS or $\mathrm{CCl}_{4}$ injection (figure 3A-C). Furthermore, LPS treatment downregulated $B M P-9$ expression in cultured HSCs (figure 3D).

Corresponding to the observed antiproliferative effects of BMP-9 on HCs (figure 2B), the drop of BMP-9 expression after $\mathrm{PH}$ (figure 3C) as well as after one injection of $\mathrm{CCl}_{4}$ (figure 3A) coincided with previously described time points of enhanced HC proliferation, which peaks $24-48$ hours after $\mathrm{PH}^{38}$ and 48 72 hours after $\mathrm{CCl} 4$ injection. ${ }^{43}$ In line with this, expression levels of the proliferation cell nuclear antigen were rapidly upregulated after a single injection of LPS and thereby opposed the BMP-9 levels at early time points (8 hours; figure 3B). We next examined the outcome of counterbalancing the downregulation of endogenous BMP-9 expression by exogenous BMP-9 at early time points after induction of damage. Indeed, injection of recombinant BMP-9 resulted in a significant enhancement of liver damage as reflected by increased circulating levels of lactate dehydrogenase (LDH), aspartate aminotransferase (AST) and alanine transaminase (ALT) on day 2 after $\mathrm{PH}$ (figure 4A). Moreover, overall proliferation was significantly reduced in BMP-9-treated animals (figure 4B), in spite of enhanced mRNA expression of the proproliferative cytokines CTGF and VEGF (figure 4C). 

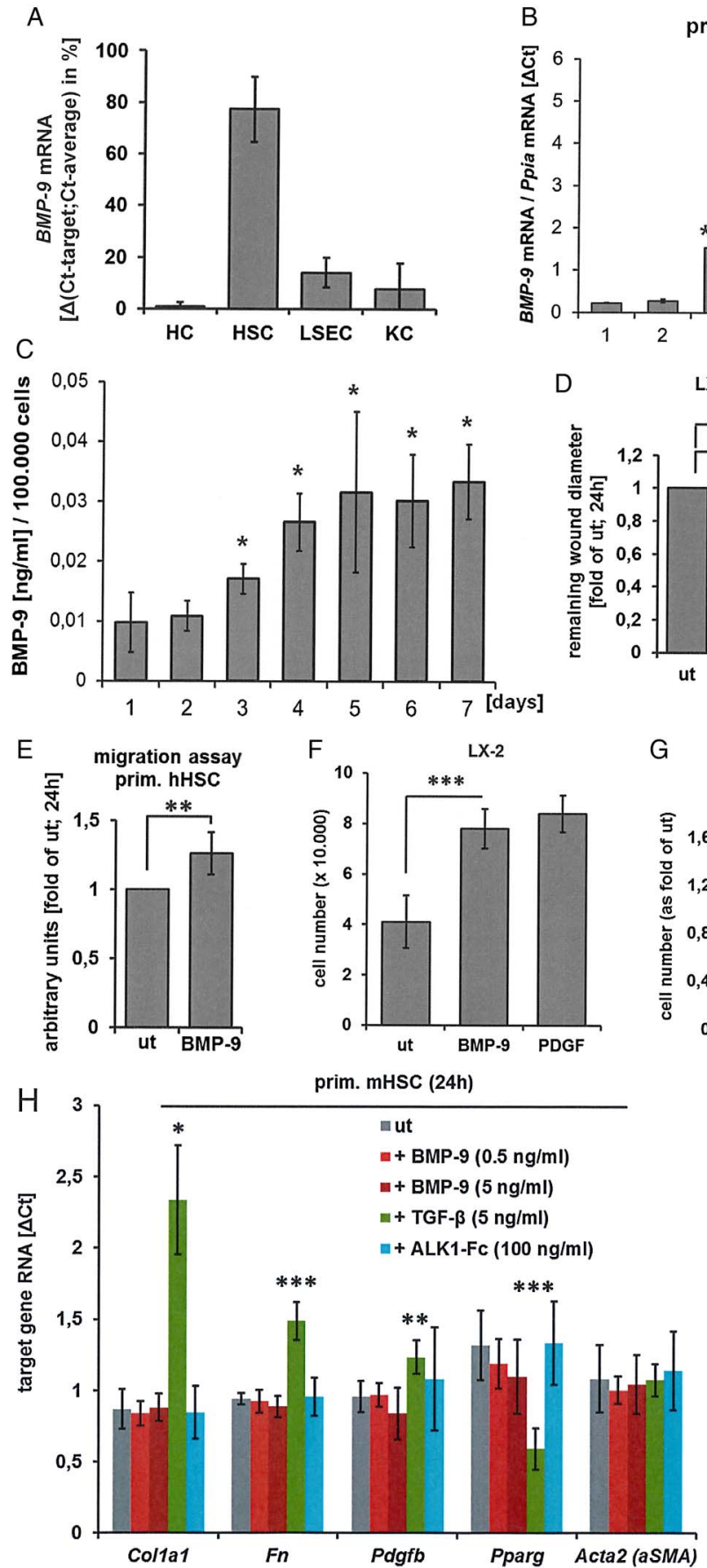

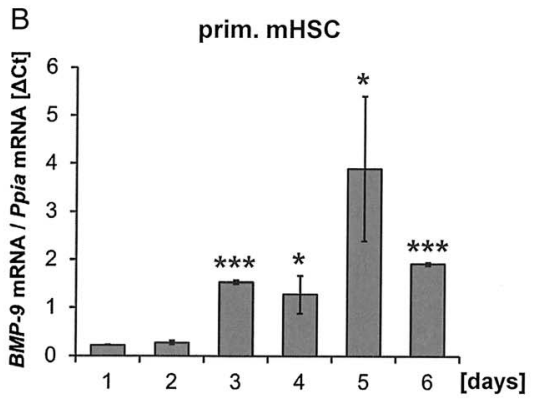

D

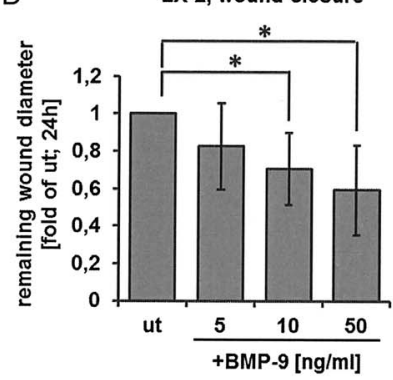

$\mathrm{G}$

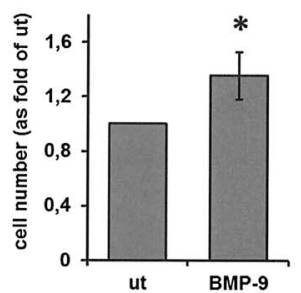

Figure 1 Hepatic stellate cells (HSCs) are source and target of bone morphogenetic protein (BMP)-9. (A) Four different liver cells types (hepatocytes (HCs), HSCs, liver sinusoidal endothelial cells (LSECs) and Kupffer cells (KCs)) were simultaneously isolated from healthy mouse livers, directly lysed and total RNA was purified. BMP-9 expression levels were determined by real-time PCR. Data are expressed as average values \pm SD (derived from $\mathrm{n}=8$ isolations). Because no housekeeping gene was equally expressed in all cell types, the $\Delta \mathrm{Ct}$ for $B M P-9$ versus the average $\mathrm{Ct}$ of all four samples per experiment was calculated and expressed as \% of total expression. (B) BMP-9 mRNA levels during in vitro activation (up to 6 days of culture) of primary mouse HSCs. Significant changes are indicated in relation to the 1-day time point. Ct values for $B M P-9$ were normalised to the housekeeping gene Ppia. (C) BMP-9 secretion from in vitro activated HSCs, measured by ELISA using samples from the conditioned medium of cultured primary mouse HSCs. Significant changes are indicated in relation to the 1-day time point. (D) Scratch assay, performed with LX-2 cells (human HSC cell line). (E) Migration assay, performed with primary human HSCs (average $\pm S D$ of $n=7$ cell isolations). LX-2 (F) or primary human HSCs (passage 3-5) (G) were cultured with or without BMP-9 $(5 \mathrm{ng} / \mathrm{mL})$ for 72 hours and cells were counted. As positive internal control, LX-2 cells were stimulated with platelet derived growth factor (PDGF)-BB $(20 \mathrm{ng} / \mathrm{mL})$ as indicated. The graphs show the average cell numbers (for $\mathrm{LX}-2(\mathrm{~F})$ : $\mathrm{n}=3$ experiments; for $(\mathrm{G})$ primary cells from four different donors were used) \pm SD. (H) Expression of HSC activation markers (Col1a1, fibronectin (fn), PDGF-B (pdgfb), Ppar $\gamma$ (pparg) and $\alpha S M A$ ) was determined by real-time PCR in primary mouse HSCs (average of $n=3$ cell isolations \pm SD) 24 hours after stimulation as indicated. (I) Primary human HSCs (passage 3-5, derived from three different donors) were stimulated with BMP-9 (5 ng/mL) for 72 hours and expression of Col1a1 was determined by real-time PCR. Statistical differences were classified as follows: ${ }^{*} p<0.05 ;{ }^{* *} p<0.001$; ${ }^{* *} \mathrm{p}<0.0001$. ALK, activin-like kinase; Ppia, peptidylprolyl isomerase $\mathrm{A} ; \alpha S M A, \alpha$ smooth muscle actin; TGF, transforming growth factor; ut, untreated. 

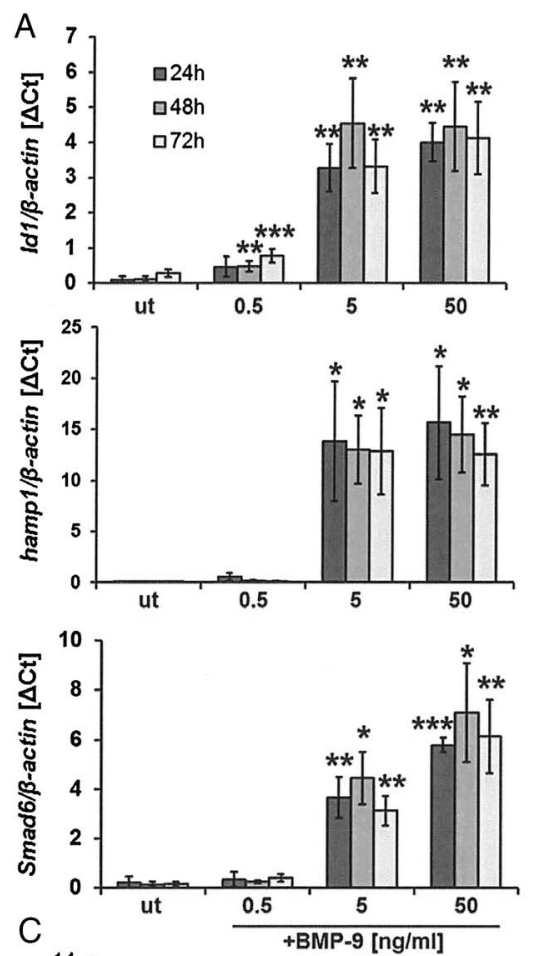

B<smiles></smiles>
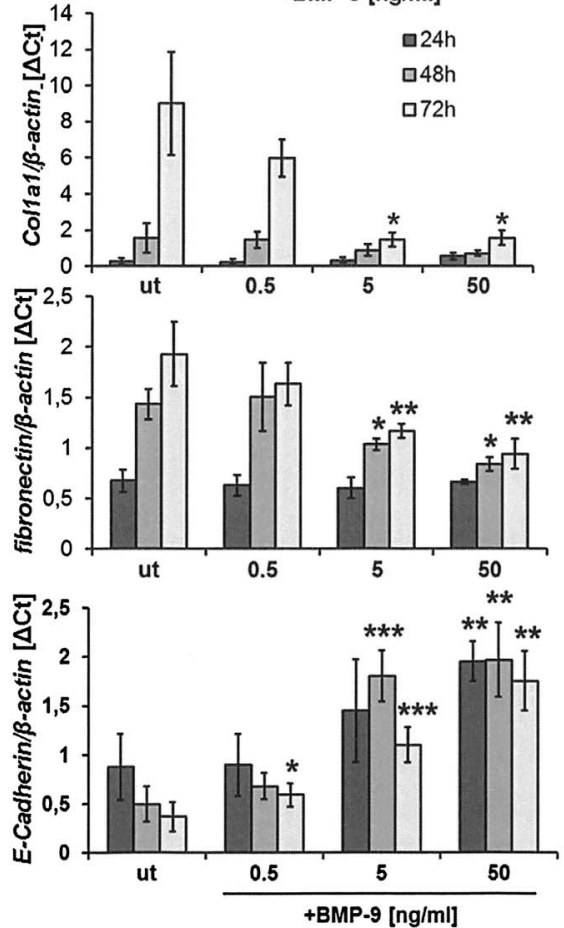

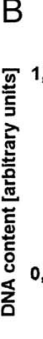
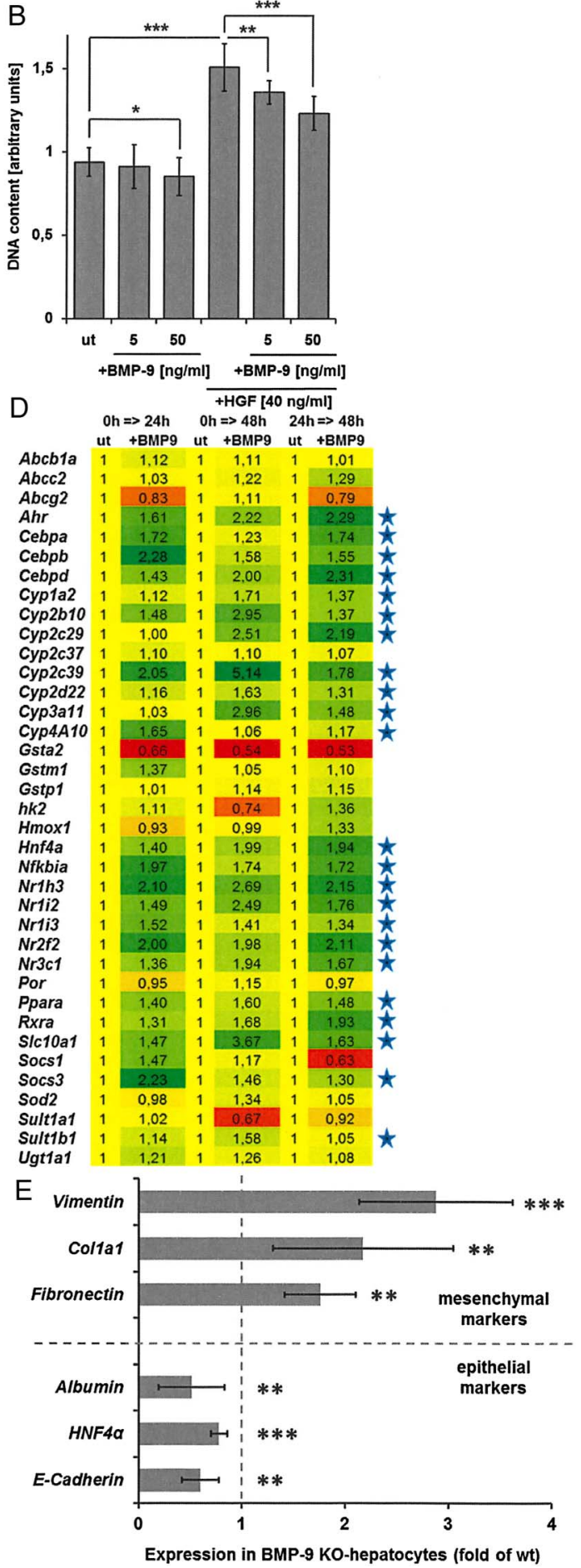

Figure 2 Effects of bone morphogenetic protein (BMP)-9 on primary mouse hepatocytes in vitro. (A) Induction of mRNA expression of classical BMP-target genes (Id1, hepcidin and Smad6) was analysed by real-time PCR. Data are expressed as average values \pm SD. Ct values for the target genes were normalised to the housekeeping gene $\beta$-actin. Significant changes are indicated in relation to the corresponding time point of the untreated (ut) samples. (B) Using a Sybr Green I-based assay DNA levels in hepatocytes were determined within 48 hours of culture with the indicated stimulations. Addition of hepatocyte growth factor (HGF) $(40 \mathrm{ng} / \mathrm{mL})$ potently triggered DNA synthesis which was attenuated by co-treatment with BMP-9 (5 and $50 \mathrm{ng} / \mathrm{mL}$ ). (C) Real-time PCR results showing that with prolonged culture of primary hepatocytes, the cells continuously induce expression of mesenchymal proteins like collagen $1 \mathrm{a} 1$ and fibronectin and reduce expression of the epithelial cadherin (E-Cadherin). In the presence of BMP-9, these regulations were significantly inhibited. Data are expressed as in panel A. (D) Hepatocytes were cultured in the presence or absence of BMP-9 $(5 \mathrm{ng} / \mathrm{mL})$ for either 24 hours ( $0 \geq 24$ hours), 48 hours ( $0 \geq 48$ hours) or first for 24 hours without and then another 24 hours with BMP-9 ( 24 hours $\geq 48$ hours) and the mRNA expression levels of 37 proteins involved in drug metabolisation processes were investigated by real-time PCR using Fluidigm analyses. The heatmap illustrates changes of ADME gene expression signatures in hepatocytes upon BMP-9 treatment and shows that approximately $60 \%$ of analysed genes are higher expressed (threshold 1.5-fold, marked with big asterisk) at least at one time span upon BMP-9 stimulation. (E) Expression of mesenchymal and epithelial marker genes were analysed by real-time PCR in freshly isolated hepatocytes from wild-type versus BMP-9 KO mice. Statistical differences were classified as follows: ${ }^{*} p<0.05 ;{ }^{* *} p<0.001 ;{ }^{* * *} p<0.0001$. 
A
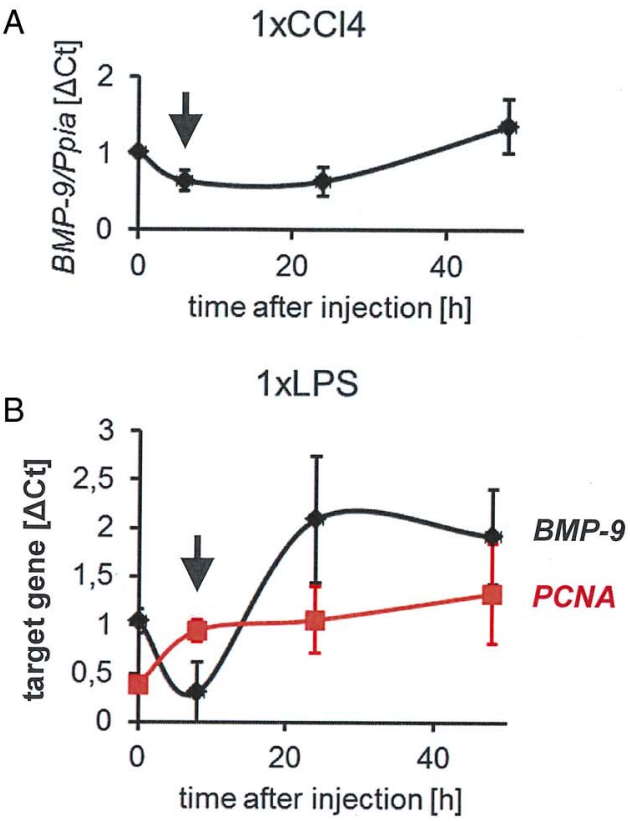

C
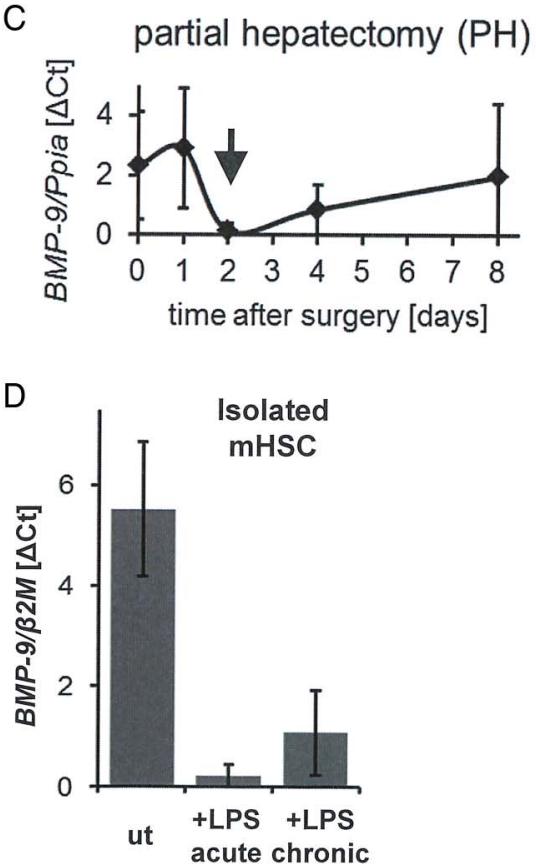

Figure 3 Transient downregulation of BMP-9 expression on acute liver damage. To cause conditions of acute liver damage followed by wound-healing/regeneration processes, mice were either injected once (intraperitoneally) with $\mathrm{CCl}_{4}$ (A) or with lipopolysaccharide (LPS) (B) or underwent partial hepatectomy $(\mathrm{PH})(\mathrm{C})$. At the indicated time points, the animals were sacrificed, the livers were preserved and total RNA was isolated. Levels of $B M P-9$ or $P C N A$ were determined by real-time $P C R$ and are plotted as average of normalised values \pm SD. For the zero-hour time points, livers of age matched, untreated animals were used. The arrows indicate the time points of lowest BMP-9 expression in each model. (D) Primary mouse hepatic stellate cells (HSCs) were cultured for 8 days (ut). LPS (100 ng/mL) was either added for 24 hours (from day 7 to day 8; 'acute') or constantly (from day 1 to day 8; 'chronic') and total RNA was isolated. Levels of BMP-9 mRNA were determined by real-time PCR and are expressed as average of normalised values $\pm S D$. $\beta 2 M, \beta 2$ microglobulin (housekeeping gene); $B M P-9$, bone morphogenetic protein 9; Ppia, peptidylprolyl isomerase A (housekeeping gene); $P C N A$, proliferation cell nuclear antigen; ut, untreated.
Lack of BMP-9 in vivo ameliorates liver fibrosis upon repeated injections of $\mathrm{CCl}_{4}$

To analyse long-term BMP-9 effects, we interfered with BMP-9 signalling, using an adenovirus expressing a soluble form of the BMP-9 type I receptor, ALK1 (AdALK1-Fc). In contrast to BMPs, TGF- $\beta$ first binds to its type II receptor (T $\beta$ RII). TGF- $\beta /$ T $\beta$ RII complex associates only thereafter with a type I receptor. The direct affinity of TGF- $\beta$ alone to any type I receptor (ALK1 or ALK5) is low (reviewed in $^{44}$ ). Therefore, ALK1-Fc protein selectively targets BMP-9 and does not inhibit TGF- $\beta$ signalling. To verify this and to also confirm that ALK1-Fc did not neutralise the effects of other BMPs, we performed western blot analyses for phosphorylated SMAD proteins (see online supplementary figure S4A, B). SMAD-1 phosphorylation by BMP-9 was efficiently inhibited by ALK1-Fc (see online supplementary figure S4C). Moreover, chronic $\mathrm{CCl}_{4}$-treated mice that received AdALK1-Fc had strongly reduced levels of circulating BMP-9 compared with those receiving $\mathrm{CCl}_{4}$ and a control virus $\mathrm{AdFc}$ (see online supplementary figure S4C).

Using this approach, we next examined the consequences of BMP-9 neutralisation under conditions of chronic liver damage. Liver fibrosis in mice was experimentally induced by repeated injections of $\mathrm{CCl}_{4}$. One group of animals served as solvent control $\left(\mathrm{CCl}_{4}+\right.$ saline $)$, a second group received a control virus $\left(\mathrm{CCl}_{4}+\mathrm{AdFc}\right)$ and BMP-9 was neutralised in the third group by injecting an adenovirus expressing ALK1-Fc $\left(\mathrm{CCl}_{4}+\mathrm{AdALK} 1-\mathrm{Fc}\right)$. Animals receiving repeated injections of $\mathrm{CCl}_{4}$ for 4 weeks developed fibrosis, which was significantly reduced by AdALK1-Fc (figure 5A, B). When analysing RNA levels for collagen in the livers of these animals, we found a correspondingly reduced expression in the AdALK1-Fc group (figure 5C). Expression of the BMP target gene Id1 was also strongly reduced, implying that BMP-9 induced Id1 expression during fibrogenesis, which was in line with our previous observation that HSCs upregulate $I d 1$ expression during activation. ${ }^{27}$ The data further show that BMP-9 expression (just like that of TGF- $\beta$ ) increases with fibrosis development. While this rise in BMP-9 levels was strongly prevented by AdALK1-Fc, TGF- $\beta$ levels remained elevated (figure 5C). Immunostaining for cleaved caspase- 3 showed significantly reduced overall apoptosis rates in AdALK1-Fc-treated animals (figure 5D). Robustness of these results was confirmed in mice with genetic depletion of BMP-9 in the $\mathrm{CCl}_{4}$-induced liver fibrosis model, where lack of BMP-9 signalling in BMP-9 knockout mice led to a milder development of fibrosis, as compared with controls (figure 6A). As in the AdALK1-Fc setup, upregulation of $\alpha$ SMA protein was significantly reduced in the $\mathrm{CCl}_{4}$-treated BMP-9 $\mathrm{KO}$ mice compared with the wild types (figure $6 \mathrm{~B}, \mathrm{C}$ ). Also here, BMP-9 mRNA expression was induced by $\mathrm{CCl}_{4}$ in the wild types and TGF- $\beta$ mRNA expression was still enhanced even in the absence of BMP-9 and despite a decreased fibrosis (figure 6D). In accordance with the Sirius red staining results shown in figure 6A, induction of Col1a1 was significantly reduced in the $\mathrm{KO}$ mice (figure 6D). Changes in fibronectin and desmin expression were not significantly different between $\mathrm{CCl}_{4}$-treated wild types and BMP-9 KO mice but in both cases basal expression was enhanced in the BMP-9 KO mice (see online supplementary figure S5B). In contrast to the AdALK1-Fc approach, upregulation of the BMP-target gene Id1 still also occurred in the absence of BMP-9 (figure 6D), which might be the result of adaptations in the BMP signalling network which had time to develop in the $\mathrm{KO}$ mice but not in the AdALK1-Fc-treated animals. Hepcidin, another BMP-target gene, was not changed by $\mathrm{CCl}_{4}$, but was generally 
Figure 4 High levels of bone morphogenetic protein (BMP)-9 lead to enhanced tissue damage reduced proliferation and enhanced CTGF and VEGF expression 2 days after partial hepatectomy ( $\mathrm{PH})$. $\mathrm{PH}(\mathrm{n}=6-8$ animals per group) was performed and recombinant BMP-9 (4 ng per g body weight) or equal amounts of phosphate buffered saline (PBS) were injected intraperitoneally every 24 hours. (A) After 2 days, the animals were sacrificed, blood was preserved and levels of LDH, AST and ALT were determined. All differences between the PBS and BMP-9 groups were statistically significant $(p<0.05)$. (B) Proliferation was determined by immunostaining for Mki67. One representative picture per group is shown. The graph shows the average amount of positive staining per surface area (as calculated from five randomly chosen areas per mouse using ImageJ software). (C) Levels of VEGF and CTGF mRNA in total liver lysates (day 2 after $\mathrm{PH}$ ) were determined by real-time PCR and are expressed as average of normalised values $\pm S D$. $C T G F$, connective tissue growth factor; Ppia, peptidylprolyl isomerase $A$ (housekeeping gene); VEGF, vascular endothelial growth factor.
A

LDH
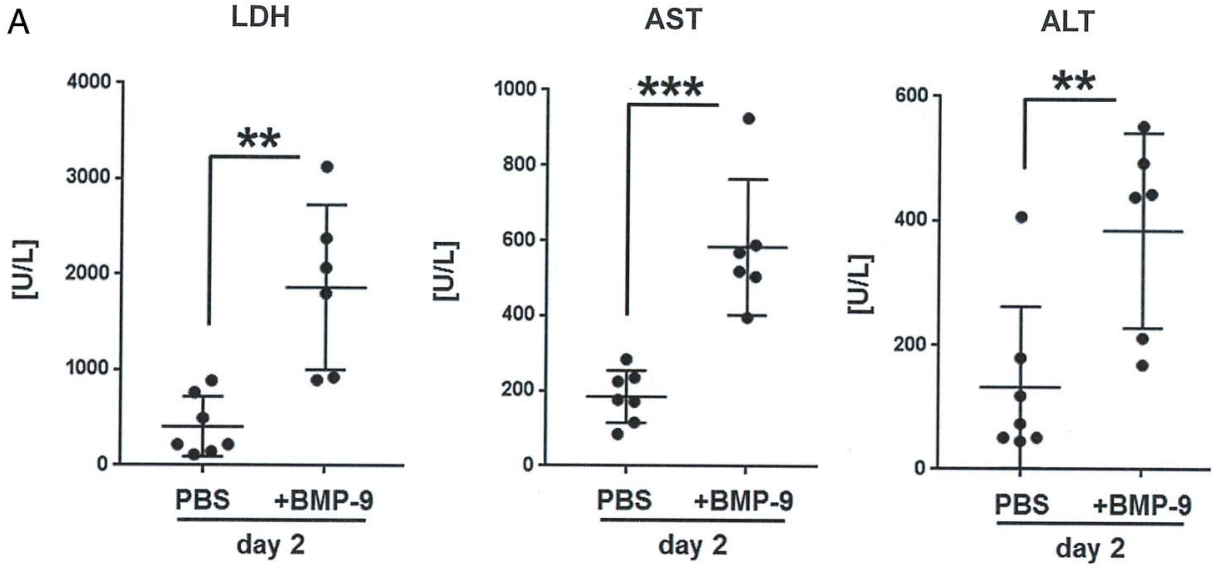

B
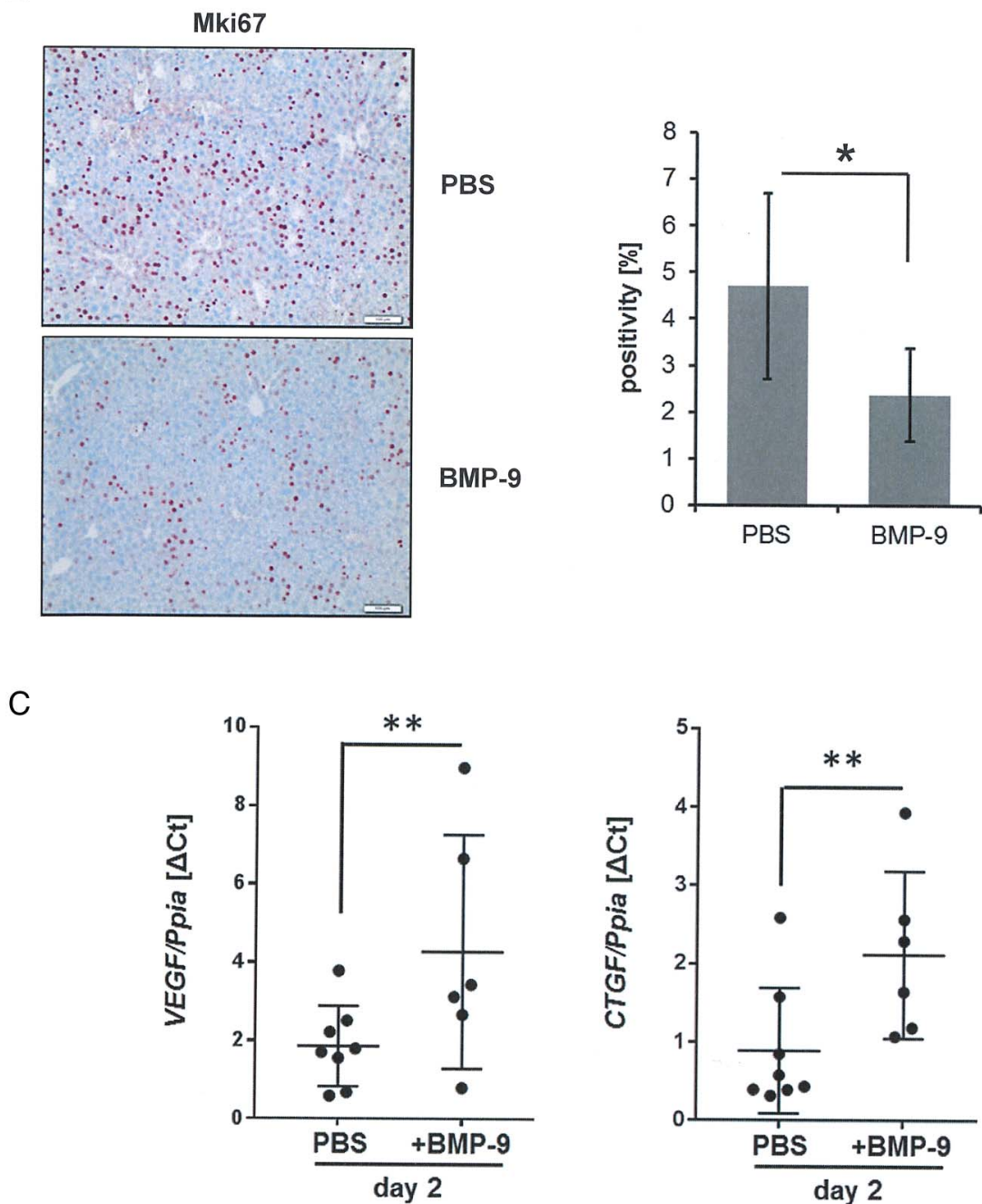

almost absent in the BMP-9 KO mice (see online supplementary figure S5B), indicating that without BMP-9 hepcidin seems to be generally low expressed. Smad6 expression was unchanged in $\mathrm{KO}$ mice compared with wild types and although there was a tendency of reduced expression of the epithelial marker E-Cadherin in the KO mice, in whole liver lysates this difference was not statistically relevant (see online supplementary figure S5B). As expected, the liver damage markers AST and ALT showed a clear tendency of reduction in the serum of the
$\mathrm{CCl}_{4}$-treated $\mathrm{KO}$ mice compared with wild type (see online supplementary figure S5B) further evidencing a decreased liver damage in the BMP-9 KO mice. Overall proliferation in the $\mathrm{CCl}_{4}$-treated $\mathrm{KO}$ mice as determined by immunostaining against Ki67 was significantly reduced compared with the wildtype animals (figure 6E).

Thus, two different experimental approaches both supported the conclusion that high levels of BMP-9 facilitate $\mathrm{CCl}_{4}$ induced liver fibrogenesis in mice. 
A
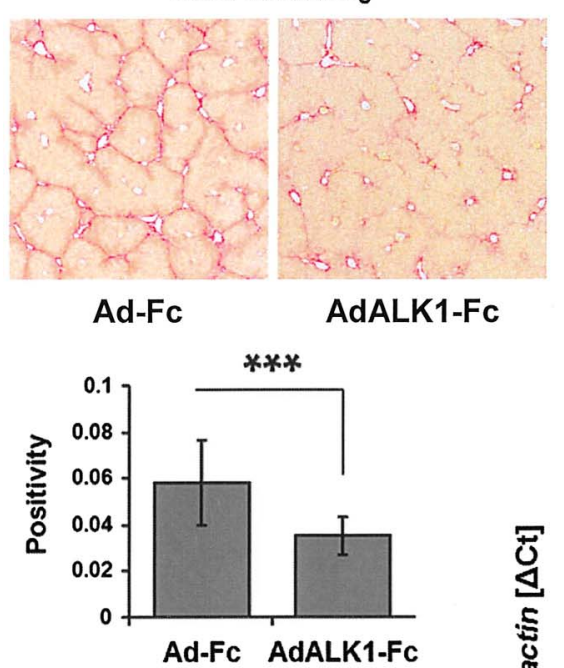

B

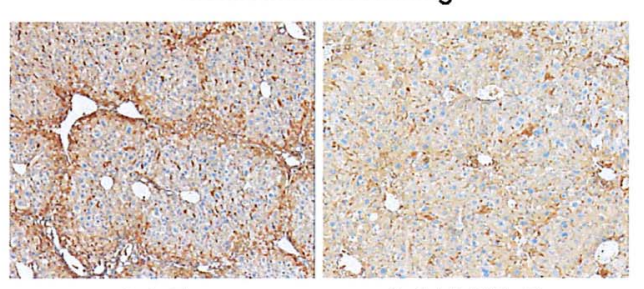

Ad-Fc

Id1

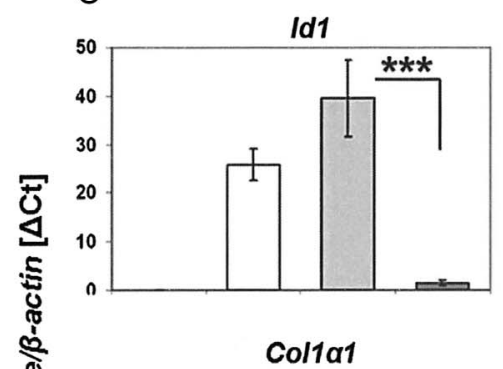

AdALK1-Fc

BMP-9

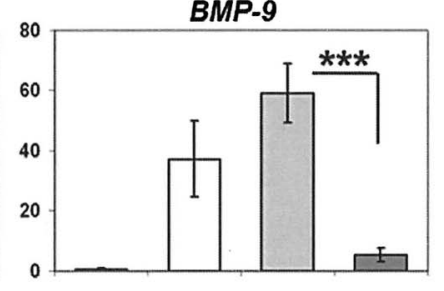

TGF- $\beta$

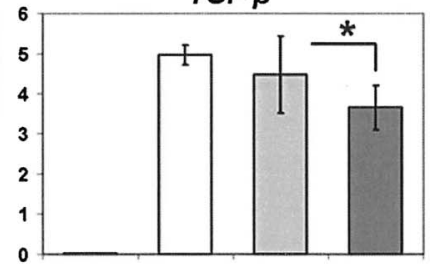

no $\mathrm{CCl}_{4}$

$\mathrm{CCl}_{4}+$ saline

$\mathrm{CCl}_{4}+\mathrm{Ad}-\mathrm{Fc}$

$\mathrm{CCl}_{4}+$ AdALK1-Fc
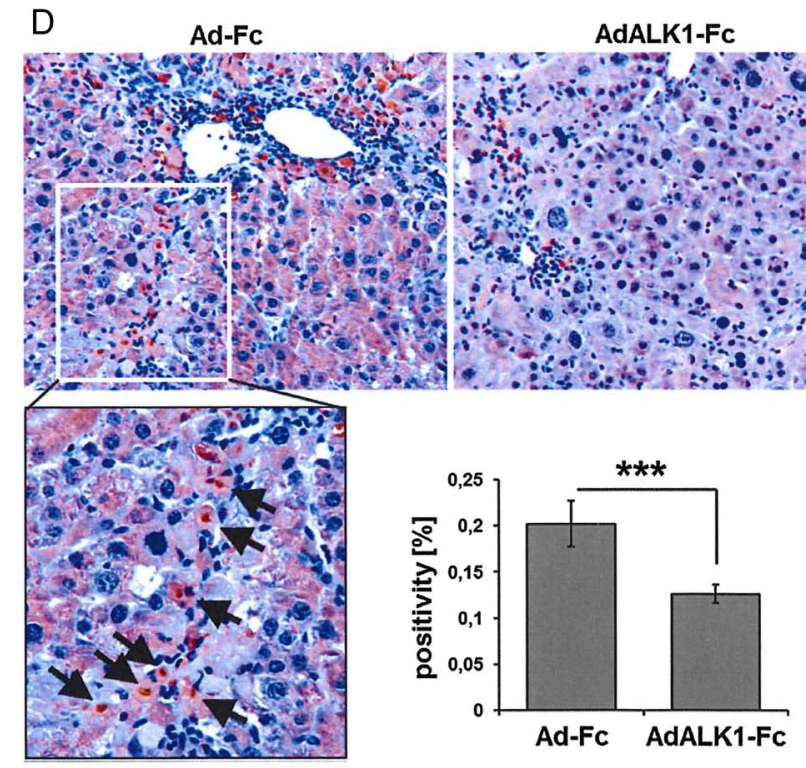

Figure 5 Sequestration of bone morphogenetic protein (BMP)-9 reduces fibrogenesis in vivo. An activin-like kinase 1 (ALK1)-Fc overexpressing adenovirus (AdALK1-Fc) was injected intraperitoneally (once) to mice which additionally received three injections of $\mathrm{CCl}_{4}$ per week for a total of 4 weeks. An adenovirus equal to AdALK1-Fc but lacking the receptor sequence (AdFc) was used as control. (A) $\mathrm{CCl}_{4}$ led to a massive deposition of fibrous matrix within the liver as determined by Sirius red staining which was significantly reduced by co-application of AdALK1-Fc (the graph shows the quantification of the staining intensities). (B) Immunohistochemical stainings for $\alpha$ smooth muscle actin ( $\alpha$ SMA) (representative pictures). (C) Real-time PCR analyses using total liver lysates showing that $\mathrm{CCl}_{4}$-mediated fibrogenesis was accompanied by increased expressions of $B M P$-9, Id1, collagen I and TGF- $\beta$ mRNAs. All three were reduced significantly by AdALK1-Fc. (D) Immunohistochemical stainings for cleaved caspase-3

(reddish-brown colour), representative pictures and quantification of staining intensities of whole section scans from $n=5$ animals per group (graph). The arrows point to individual positive cells located along a fibrotic septum. In the AdALK1-Fc group, the amount of cleaved caspase-3 positive staining was significantly reduced.

\section{Potential role of BMP-9 in human liver fibrosis}

To address the question if our results with mice are transferable to the human situation, we performed immunostaining against
BMP-9 in cryosections from normal and fibrotic human livers (figure 7). We found positive staining in normal liver in stellateshaped, non-parenchymal cells and in the walls of larger blood 
A

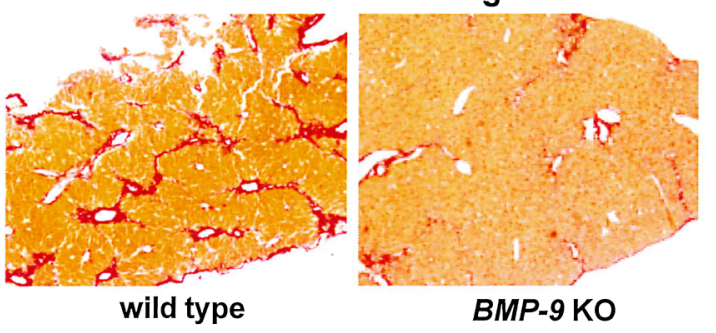

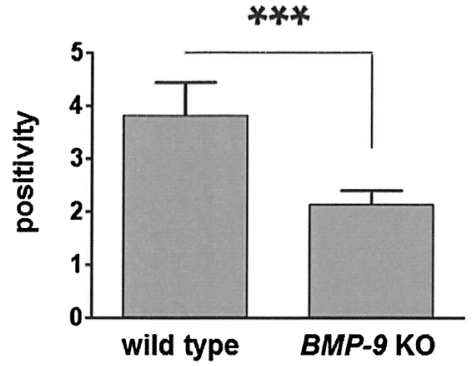

B
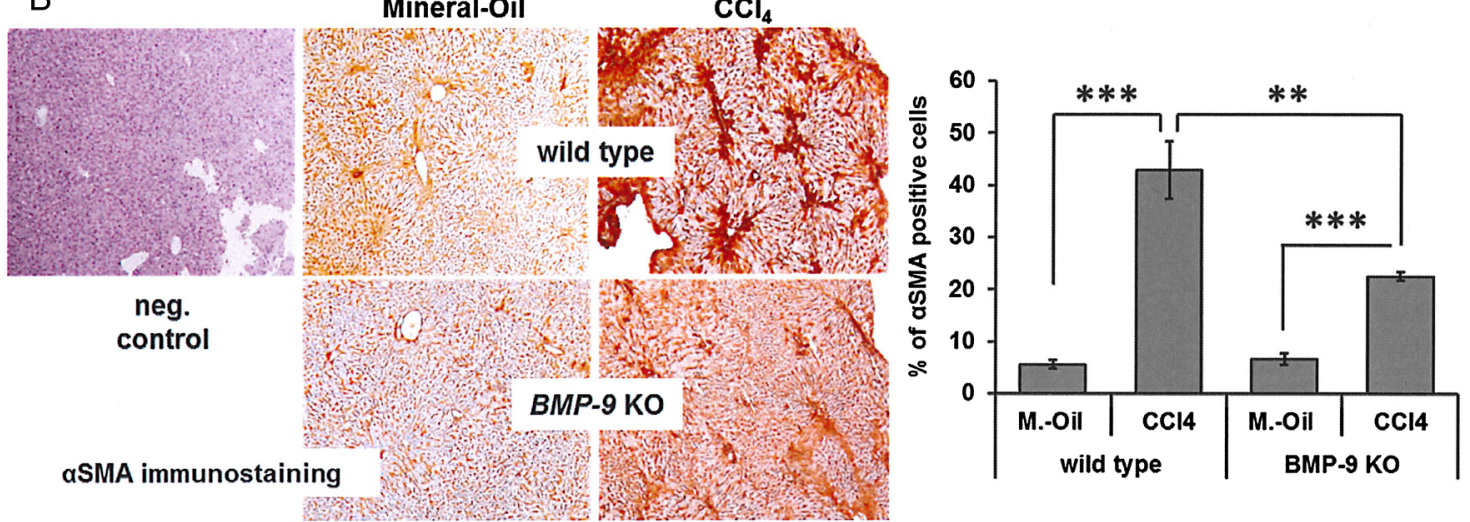

C
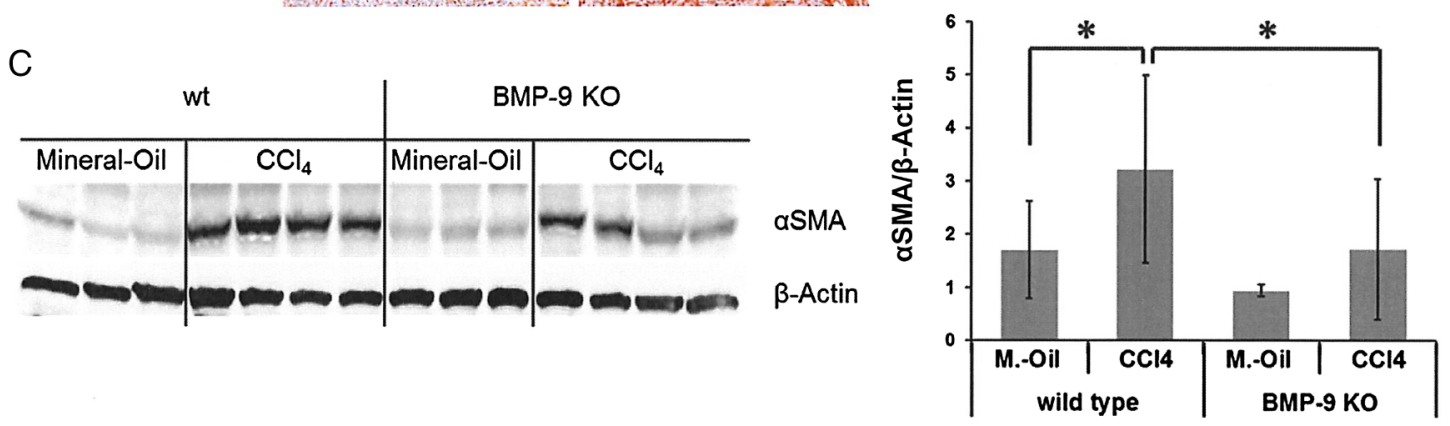

Figure 6 Bone morphogenetic protein (BMP)-9 knockout mice develop less fibrosis upon $\mathrm{CCl}_{4}$ challenge in vivo. Wild-type or $B M P-9 \mathrm{KO}$ mice were injected intraperitoneally with $\mathrm{CCl}_{4}$ or mineral oil for 8 weeks. (A) In the wild-type animals, $\mathrm{CCl}_{4}$ led to a massive deposition of fibrous matrix within the liver as determined by Sirius red staining which was significantly reduced in BMP-9 KO mice (the graph shows the quantification of the staining intensities). (B) Immunohistochemical stainings for $\alpha$ smooth muscle actin ( $\alpha S M A)$ (representative pictures and quantification). The photo on the left shows the result of the negative control (no primary antibody added). (C) Investigation of aSMA protein expression by immunoblot analysis (representative western blot plus quantitative densitometric analysis of samples from $n=5-10$ mice per condition). (D) Expression levels of $B M P-9$, TGF- $\beta$, Collagen I (Col1a1) and Id1 were investigated by real-time PCR in whole liver samples and were normalised to the housekeeping gene Gusb. Data are expressed relative to untreated samples (assigned an arbitrary value of 1 ) and are mean \pm SEM. of at least seven animals. (E) Immunohistochemical detection of Ki67 in liver sections. For quantification, positive cells from a total of 16 fields of sections from at least four animals per group were counted and are presented as average \pm SD.

vessels, especially with onset of HSC activation (early fibrogenesis). This pattern fits well with the hypothesis that also in human liver HSCs located at the sinusoids and in the walls of larger vessels are principally positive for BMP-9 synthesis. Bile duct epithelium appeared rather negative. In line with this, in moderate fibrosis positive staining was found in those areas where activation of HSCs can be expected. In fully established fibrotic septae, staining seemed to be less intense, though still present.

When searching publicly available array data with human liver samples, we found two cohorts which investigated normal liver samples versus hepatitis-B-virus (HBV)-mediated damage (see online supplementary figure S6A, B). BMP-9 itself was significantly upregulated in the samples from patients with acute liver failure (GSE38941), but not significantly changed with increasing fibrosis stages (GSE84044). The co-receptor endoglin was significantly enhanced in samples of fibrosis stages 2 and 4
(GSE84044), but not in the acute liver failure cohort (GSE38941). However, expression of the BMP-9 receptor ALK1 was significantly upregulated in both cohorts, indicating that under conditions of damage the number of ALK1-positive cells and thereby the sensitivity and responsiveness to BMP-9 stimulation increases. Thereby local elevations of BMP-9 might directly affect the cellular crosstalk, for example, between activated HSCs and LSECs.

\section{DISCUSSION}

Although BMP-9 is constitutively expressed in healthy liver, ${ }^{17} 19$ knowledge about its physiological functions is still very limited $\left(\right.$ for review, see ${ }^{45}$ ). Whereas inhibition of BMP-9/ALK1 signalling is already discussed as a potential anti-angiogenic strategy in cancer $^{46}$ and clinical application of rhBMP-9 was recently presented as a potentially promising new approach to promote fracture healing, ${ }^{47}$ its possible roles during acute or chronic liver 


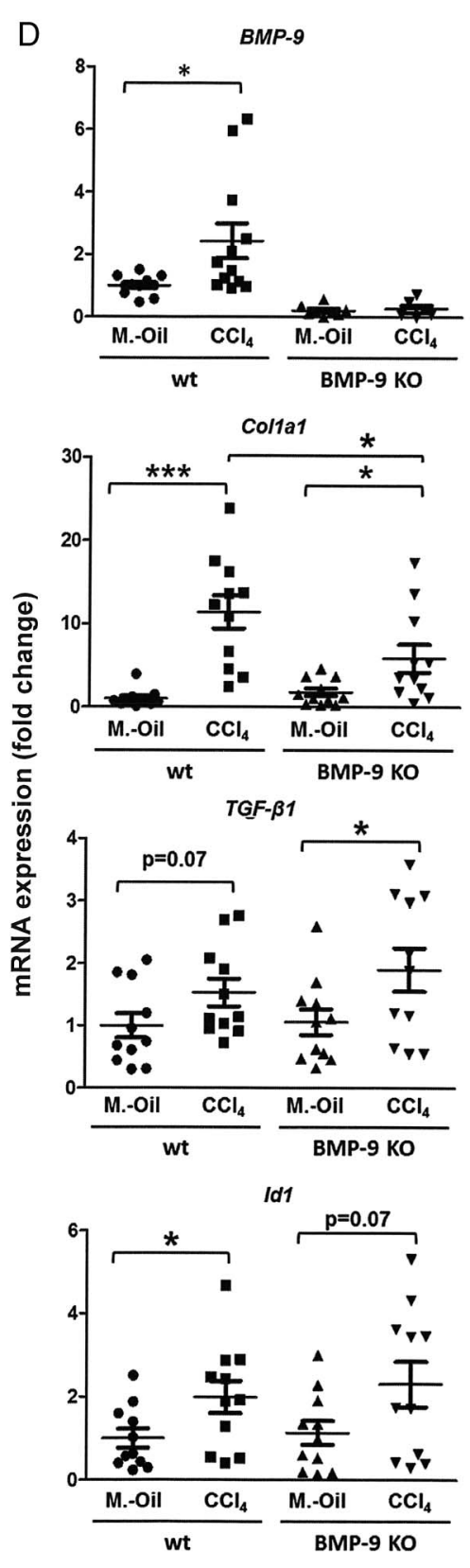

Figure 6 Continued

damage were only insufficiently investigated up to now. In the present work, we therefore addressed this point and investigated BMP-9 expression levels, cellular responses and in vivo consequences of BMP-9 signalling in liver cells in vitro as well as in diverse mouse models for acute and chronic liver damage.

The results demonstrate that (1) the HSC is the main BMP-9-producing cell type in the liver, (2) BMP-9 expression further increases when HSCs become activated leading to higher levels during fibrogenesis, (3) neutralisation of BMP-9 ameliorates fibrogenesis and (4) BMP-9 stabilises the epithelial properties of HCs and controls their proliferation in vitro as well as in vivo at early time points after acute damage.

\section{Profibrogenic action of BMP-9}

The finding that the liver is the main organ that produces BMP-9 (at least under healthy conditions) seems undoubted, ${ }^{17} 19$ but the exact hepatic cell type secreting BMP-9 was controversially reported. Miller et al ${ }^{19}$ detected high BMP-9 expression in rat liver, and specified non-parenchymal cells (HSC, LSEC and
E
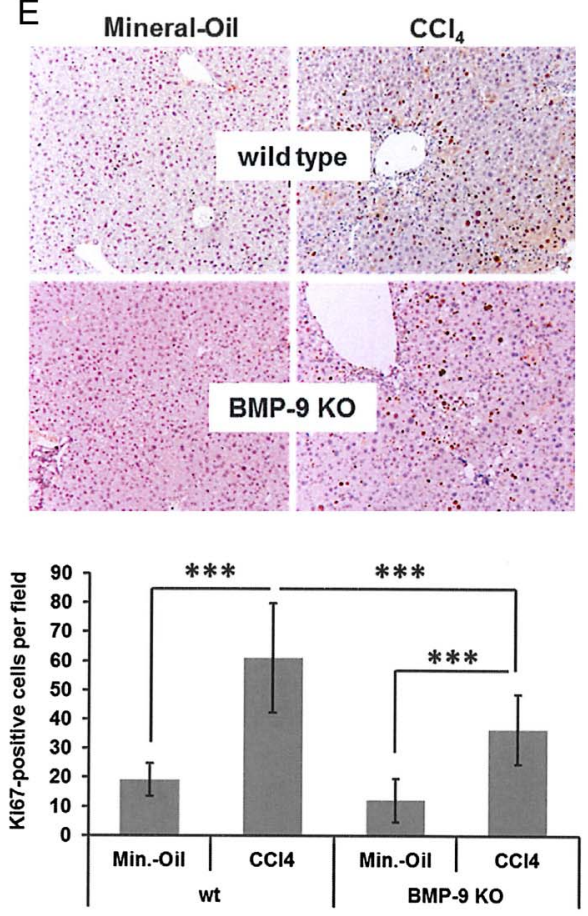

KC) but not HCs as producing cell types. Another study using human samples confirmed the highest expression of BMP-9 in liver but when analysing commercially obtained RNA samples from diverse human liver cell types (bile duct cells, HCs, HSCs and LSECs), they found highest BMP-9 expression in bile duct cells followed by HCs and only rather low expression in HSCs and LSECs. ${ }^{17}$ Our results confirm the data of Miller et al ${ }^{19}$ showing highest BMP-9 transcript expression in HSCs (figure 1A). HCs, in contrast, expressed very low, almost undetectable levels. Although we did not find evidence for a direct enhancement of activation in vitro (no significant induction of aSMA, collagen I, fibronectin or Pdgfb mRNA expression by BMP-9 stimulation and no reduction of Ppary; figure $1 \mathrm{H}, \mathrm{I})$, these cells obviously produce BMP-9 under quiescent conditions, which is further enhanced on fibroblastic activation in vitro (figure $1 \mathrm{~B}, \mathrm{C}$ ). This finding implied that liver fibrogenesis might be accompanied by enhanced presence of BMP-9 in vivo. Consistently, BMP-9 and its direct target gene Id1 are strongly upregulated at the transcript level in fibrotic livers of mice that received repeated 


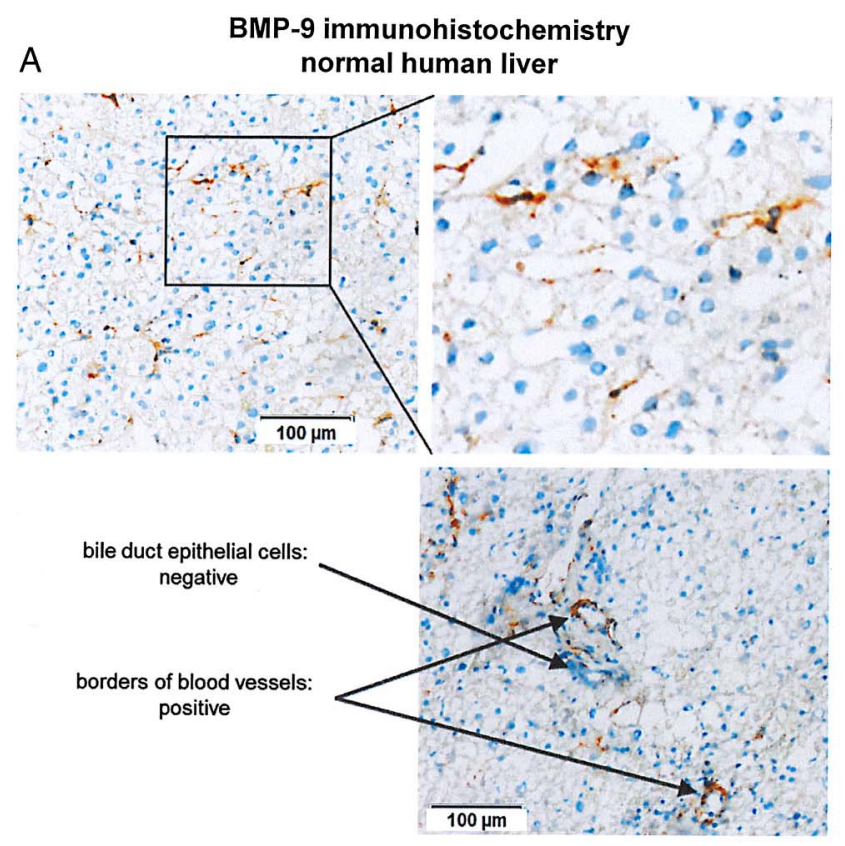

B

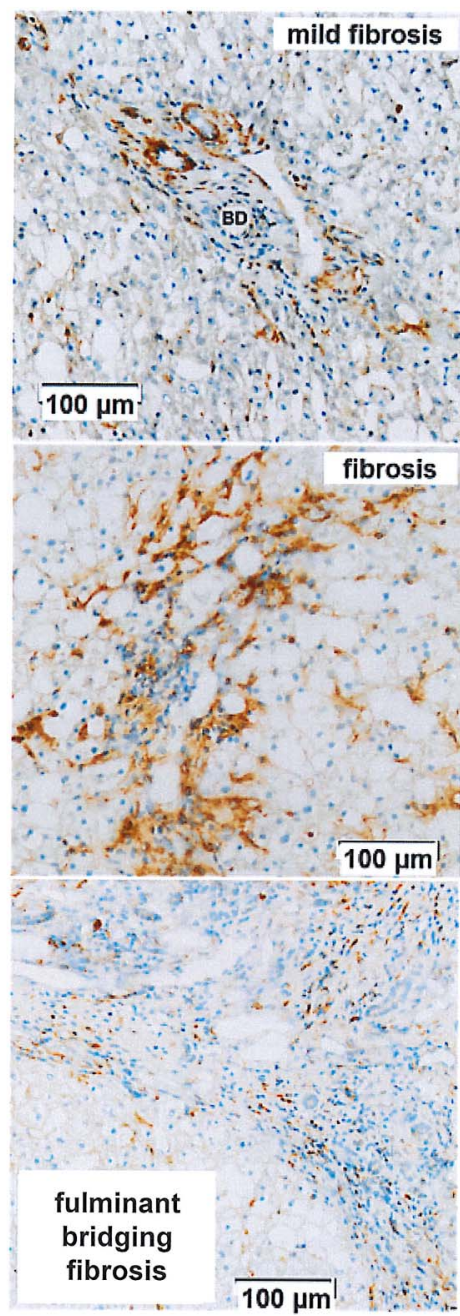

Figure 7 Representative examples of immunohistochemical stainings against bone morphogenetic protein (BMP)-9 in cryosections from (A) normal and (B) fibrotic human livers. BD, bile duct.

injections of $\mathrm{CCl}_{4}$ (figures $5 \mathrm{C}$ and $6 \mathrm{D}$ ). We further document enhanced HSC migration and proliferation by BMP-9. Based on this and the increased BMP-9 secretion from activated HSCs, locally high levels of BMP-9 at sites of liver damage where fibrosis develops can be expected and were indeed observed by immunostaining of fibrotic human liver samples (figure 7). To analyse if elevated BMP-9 expression is indeed functionally related to fibrogenesis under conditions of chronic damage (repeated injections of $\mathrm{CCl}_{4}$ ), we used two different approaches: first, we adenovirally overexpressed a soluble form of the BMP-9 receptor ALK1 (by AdALK1-Fc), which binds and thereby neutralises BMP-9 protein. Because neither TGF- $\beta$ nor other BMPs (except BMP-10) exert high affinity to ALK1 alone (in the absence of a type II receptor), ALK1-Fc selectively neutralises BMP-9 (see online supplementary figure S4). In the second approach, we used BMP-9 KO mice. On repeated injections of $\mathrm{CCl}_{4}$ for several weeks, all mice developed liver fibrosis. When BMP-9 was neutralised (by ALK1-Fc) or absent (in the $\mathrm{KO}$ mice), the degree of fibrosis was clearly reduced (figures 5 and 6). These data suggest that in the context of chronic liver injury, BMP-9 aggravates liver fibrogenesis in vivo. The underlying mechanism most likely involves enhanced migration and proliferation of activated HSCs (figure 1D-G) and at least in the
AdALK1-Fc model also induction of Id1 which we had already earlier identified as a fibrosis-regulating factor. ${ }^{27}$ In the $\mathrm{KO}$ mice treated with $\mathrm{CCl}_{4}, \mathrm{Id} 1$ expression was still significantly upregulated (figure 6D) which could be a result of adaptation processes that may have occurred in these mice. Since LSECs can directly control HSC activation ${ }^{48}$ and the BMP-9 receptor ALK1 was highly expressed in freshly isolated LSECs (see online supplementary figure S2), the profibrogenic effects of BMP-9 that we observed might as well be the result of a cellular crosstalk between HSCs and LSECs. In line with this hypothesis, we found significantly enhanced ALK1 expression in fibrotic human samples as derived from publically available array data with human liver samples (GSE38941 and GSE84044; online supplementary figure S6A, B) implying that the sensitivity of liver cells to BMP-9 stimulation should increase with fibrogenesis.

\section{BMP-9 functions as stabiliser of HC epithelial properties}

It is well established that isolated HCs in culture rapidly lose their epithelial and functional properties and that they spontaneously undergo a dedifferentiation process towards a mesenchymal cell type. ${ }^{40} 41$ This process, which exerts features of an EMT, is further enhanced in the presence of TGF- $\beta .^{40}$ On EMT, 
HCs downregulate expression of many enzymes and genes needed for proper metabolic functions of the liver. The conclusion from these findings is that only polarised (epithelial) HCs are capable of efficiently processing xenobiotics or endogenous substances. On the other hand, under conditions of damage or on malignant transformation of HCs, EMT enables the cells to proliferate and to become motile. BMP-9 exerted significant antiproliferative and anti-EMT activities on primary cultured mouse HCs in vitro (see figure $2 \mathrm{~B}, \mathrm{C}$ and online supplementary figure S3). In addition, BMP-9 led to enhanced and preserved expression of important drug metabolising enzymes, especially cytochrome P450 oxidases (figure 2D) and BMP-9 KO HCs expressed significantly less epithelial and more mesenchymal markers than wild-type cells (figure 2E). These findings imply that the basal presence of BMP-9 in healthy liver might contribute to maintain functionality of parenchymal cells. Nevertheless, since BMP-9 knockout mice are viable and fertile, showing no overt phenotype, ${ }^{12}$ these basic hepatic functions of BMP-9 seem to be largely dispensable or can become compensated by other, so far not identified factors or mechanisms.

Our observation that BMP-9 acts as an antiproliferative and stabilising factor on primary HCs fits well to its previously reported properties as 'quiescence factor' for the (healthy) epithelium. ${ }^{20}$ Nevertheless, we and others also reported EMT-promoting effects of BMP-9 on hepatocellular carcinoma cells. $^{6}{ }^{26}$ This, together with the finding that BMP-9 neutralising agents are already in clinical trials as anti-angiogenic strategy against cancer growth ${ }^{46}$ makes us conclude that at least in HCs and endothelial cells, BMP-9 exerts completely opposite functions in malignant versus non-malignant conditions. How these opposing functions are mechanistically mediated and controlled is not known but might be related to diverse expression levels of the individual receptors and co-factors, or might be brought about by crosstalk of BMP-9 signalling with other pathways.

\section{On acute liver damage, BMP-9 needs to be transiently downregulated}

We then investigated the hepatic expression levels of BMP-9 in three different mouse models of acute liver damage/regeneration, namely $\mathrm{PH}$ and single injections of either LPS or $\mathrm{CCl}_{4}$. In each of these models, we found a transient reduction of BMP-9 expression levels at early time points (figure 3A-C).

Considering that almost any kind of liver injury goes along with an increase of gut-derived bacterial toxins such as LPS in the blood, ${ }^{49-53}$ it is well conceivable that this effect of acute liver injury on BMP-9 expression may be due to inhibitory effects of LPS on HSCs, which represent the major source of BMP-9 (figure 1A). In line with this assumption, LPS treatment results in a downregulation of BMP-9 levels in liver tissue in vivo (figure $3 \mathrm{~B}$ ) and strongly suppresses BMP-9 expression levels in HSCs (figure 3D) in vitro. Similar to KCs and sinusoidal endothelial cells, HSCs also express the LPS receptor Toll like receptor (TLR)-4 and respond to LPS treatment with proinflammatory signalling. ${ }^{54}$ We further found that counteracting such drop of BMP-9 in vivo 2 days after PH resulted in significantly enhanced liver damage (figure 4A). In accordance with the above-described antiproliferative effects of BMP-9 on HCs, these animals showed a reduced level of Mki67-positive cells (figure 4B). This was accompanied by significantly upregulated expressions of the proproliferative cytokines VEGF and CTGF mRNA (figure 4C), which might be a mechanism of compensation of the antiproliferative effect of BMP-9.

These data support the concept that rapid reduction of BMP-9 expression (possibly via LPS) after acute damage might be needed to allow for transient HC proliferation and plasticity, features that are essential for optimal wound healing. Ongoing studies aim at further analysing the interplay of BMP-9 with LPS and its possible role in modulating inflammatory processes in the liver.

Under conditions of chronic damage (repeated injections of $\mathrm{CCl}_{4}$ ), absence or neutralisation of BMP-9 reduced fibrogenesis and in this context overall proliferation was also reduced (figure 5D) indicating that the antiproliferative effects of BMP-9 on HCs might be rather important during acute damage than during chronic processes. This hypothesis is supported by our observation that the rapid reduction in BMP-9 expression in the three models of acute damage (figure $3 \mathrm{~A}-\mathrm{C}$ ) always correlated with the onset of HC proliferation (for the LPS injection model this is shown in figure 3B, for CCI4 injection and partial hepatectomy the proliferation time courses have been reported previously ${ }^{29}{ }^{43}$ ), similar to the results previously published by Mogler $e t a l^{29}$ and Hoehme $e t a l^{43}$.

At first sight, it may seem contradictory that BMP-9 on the one side optimises HC polarisation and functionality, but on the other side high levels of BMP-9 seem to generally enhance liver damage. We think that the functions of BMP-9 as a stabiliser of the parenchyma-although possibly beneficial under healthy conditions-might become impedimental under conditions of damage, where actions such as proliferation and plasticity are essentially needed, at least transiently. In addition, it seems very probable that BMP-9 may indirectly affect HSC activation and fibrogenesis by acting on other BMP-9-responsive liver cell types, like LSEC, which we showed to express even higher levels of all tested BMP-9 receptors than HSC (see online supplementary figure S2). For example, capillarisation of LSECs, a feature associated with liver damage including fibrogenesis, 5566 might be affected by high levels of BMP-9.

In summary, our data show that increasing levels of BMP-9 under conditions of damage pave the way to liver fibrogenesis, whereas absence or inhibition of BMP-9 supports the road to wound healing and liver regeneration. If this concept can be further confirmed in human, neutralisation of BMP-9 could become an important therapeutic approach to maximise the efficiency of antifibrotic medications of the liver, and possibly other organs. Up to a certain degree of damage, even the sole, transient inhibition of endogenous BMP-9 activity might suffice to allow for better liver regeneration and healing.

\section{Author affiliations}

${ }^{1}$ Department of Medicine II, Medical Faculty Mannheim, Heidelberg University, Mannheim, Germany

${ }^{2}$ Division of Vascular Oncology and Metastasis, German Cancer Research Center Heidelberg (DKFZ-ZMBH Alliance), Heidelberg, Germany

${ }^{3}$ Department of Biochemistry and Molecular Biology II, Faculty of Pharmacy, Complutense University of Madrid, San Carlos Clinical Hospital Health Research Institute (IdISSC), Madrid, Spain

${ }^{4}$ Dr. Margarete Fischer-Bosch Institute of Clinical Pharmacology and University of Tuebingen, Stuttgart, Germany

${ }^{5}$ German Red Cross Blood Service Baden-Württemberg-Hessen and Institute for Transfusion Medicine and Immunohaematology, Goethe University, Frankfurt, Germany

${ }^{6}$ Department of Gastroenterology and Hepatology, Beijing You'an Hospital, Affiliated with Capital Medical University, Beijing, China

${ }^{7}$ Department of Internal Medicine I, University Hospital Regensburg, Regensburg, Germany

${ }^{8}$ Applied Tumor Immunity Clinical Cooperation Unit, National Center for Tumor Diseases, German Cancer Research Center, Heidelberg, Germany

${ }^{9}$ Department of Gastroenterology, Hepatology and Infectious Diseases, University Hospital of the Heinrich-Heine University, Duesseldorf, Germany

${ }^{10}$ Division Systems Biology of Signal Transduction, DKFZ-ZMBH Alliance, German Cancer Research Center (DKFZ), Heidelberg, Germany 
${ }^{11}$ Department of Molecular Cell Biology and Centre for Cancer Genomics, Leiden University Medical Center, Leiden, The Netherlands

${ }^{12}$ Johns Hopkins University School of Medicine, Molecular Biology and Genetics, Baltimore, USA

${ }^{13}$ Institute of Pathology, Technical University of Munich, München, Germany

${ }^{14}$ Department of Vascular Biology and Tumor Angiogenesis (CBTM), Medical Faculty

Mannheim, Heidelberg University, Mannheim, Germany

${ }^{15}$ German Cancer Consortium, Heidelberg, Germany

Acknowledgements The authors are thankful to Alexandra Mueller, Katarina Abramovic and Emine Tuezen (Medical faculty Mannheim, Heidelberg University) and Igor Liebermann (Dr Margarete Fischer-Bosch Institute of Clinical Pharmacology, Stuttgart, Germany) for excellent technical assistance and Anne Dropmann (University hospital at Mannheim) for providing TGF- $\beta 1$ primer sequences.

Contributors $\mathrm{KB}-\mathrm{H}, \mathrm{AS}, \mathrm{SD}$ and PtD did the planning for the study and are responsible for the overall content. Experiments were conducted by $\mathrm{KB}-\mathrm{H}, \mathrm{CMe}, \mathrm{CK}$ HG, AA, MT, EW, QL, FW, CH, MJH, SM-B, JA, MG, LJACH, SL, MW, CMo, CC, CE and $\mathrm{BH}$. Reporting of the data and writing of the manuscript was performed by $\mathrm{KB}-\mathrm{H}, \mathrm{CMe}, \mathrm{HG}, \mathrm{EW}, \mathrm{CH}, \mathrm{NAV}$, JGB, SM-B, UK, JA, LJACH, CM, MPE, BH, HGA, AS, SD and PtD.

Funding This study was supported by Cancer Genomics Centre Netherlands and FP7-PEOPLE-2012-ITN IT-LIVER (SD, AA, PtD, BH, AS: grant no 316549). The study was further supported by the Robert Bosch Foundation, Stuttgart, Germany, and the German Research Foundation; Contract grant numbers: 'He2458/18-1' and 'Do373/ 8-1' as well as the Federal Ministry of Education and Research grants 'The Virtual Liver' and 'LiSyM' (SD). QL was a fellow supported by the China Scholarship Council and CC by a scholarship from Wu Jin Ren Min Hospital, China. CM is supported by the Deutsche Forschungsgemeinschaft (Me4532/1-1). AA is an ESR (early-stage researcher) within the ITN. KB-H was further supported by the 'Förderprogramm ZIM des BMWi' (KF3431901AJ4) and the programme 'Entwicklung von

Alternativmethoden zur Vermeidung von Tierversuchen' granted by the 'Ministerium für Wissenschaft, Forschung und Kunst Baden-Württemberg'. S-JL was supported by the NIH grant no. R01AR060636.

Competing interests None declared.

Ethics approval The tissue bank of the National Center for Tumor Diseases (NCT, Heidelberg, Germany) in accordance with the regulations of the tissue bank and the approval of the ethics committee of Heidelberg University (Ethikvotes \# 206/207, year: 2005).

Provenance and peer review Not commissioned; externally peer reviewed.

\section{REFERENCES}

1 Wu MY, Hill CS. Tgf-beta superfamily signaling in embryonic development and homeostasis. Dev Cell 2009;16:329-43.

2 García de Vinuesa A, Abdelilah-Seyfried S, Knaus P, et al. BMP signaling in vascular biology and dysfunction. Cytokine Growth Factor Rev 2016;27:65-79.

3 Sánchez-Duffhues $\mathrm{G}$, Hiepen $\mathrm{C}$, Knaus $\mathrm{P}$, et al. Bone morphogenetic protein signaling in bone homeostasis. Bone 2015;80:43-59.

4 Wakefield LM, Hill CS. Beyond TGF $\beta$ : roles of other TGF $\beta$ superfamily members in cancer. Nat Rev Cancer 2013;13:328-41.

5 Derynck R, Zhang YE. Smad-dependent and Smad-independent pathways in TGF-beta family signalling. Nature 2003;425:577-84.

6 Herrera B, Garćia-Alvaro M, Cruz S, et al. BMP9 is a proliferative and survival factor for human hepatocellular carcinoma cells. PLoS ONE 2013;8:e69535.

7 Massagué J. TGFbeta signalling in context. Nat Rev Mol Cell Biol 2012;13:616-30.

8 Akhurst RJ, Padgett RW. Matters of context guide future research in TGF $\beta$ superfamily signaling. Sci Signal 2015;8:re10.

9 Massagué J, Gomis RR. The logic of TGFbeta signaling. FEBS Lett 2006; $580: 2811-20$

10 Chen H, Brady Ridgway J, Sai T, et al. Context-dependent signaling defines roles of BMP9 and BMP10 in embryonic and postnatal development. Proc Natl Acad Sci USA 2013:110:11887-92.

11 Scharpfenecker M, van Dinther M, Liu Z, et al. BMP-9 signals via ALK1 and inhibits bFGF-induced endothelial cell proliferation and VEGF-stimulated angiogenesis. J Cell Sci 2007:120:964-72

12 Ricard N, Ciais D, Levet S, et al. BMP9 and BMP10 are critical for postnatal retinal vascular remodeling. Blood 2012;119:6162-71.

13 Herrera B, van Dinther $M$, Ten Dijke P, et al. Autocrine bone morphogenetic protein-9 signals through activin receptor-like kinase-2/Smad1/Smad4 to promote ovarian cancer cell proliferation. Cancer Res 2009;69:9254-62.

14 Townson SA, Martinez-Hackert E, Greppi C, et al. Specificity and structure of a high affinity activin receptor-like kinase 1 (ALK1) signaling complex. J Biol Chem 2012;287:27313-25

15 Brown MA, Zhao Q, Baker KA, et al. Crystal structure of BMP-9 and functional interactions with pro-region and receptors. J Biol Chem 2005;280:25111-18.
16 Neuhaus H, Rosen V, Thies RS. Heart specific expression of mouse BMP-10 a novel member of the TGF-beta superfamily. Mech Dev 1999;80:181-4.

17 Bidart M, Ricard N, Levet S, et al. BMP9 is produced by hepatocytes and circulates mainly in an active mature form complexed to its prodomain. Cell Mol Life Sci 2012;69:313-24

18 Song JJ, Celeste AJ, Kong FM, et al. Bone morphogenetic protein-9 binds to liver cells and stimulates proliferation. Endocrinology 1995;136:4293-7.

19 Miller AF, Harvey SA, Thies RS, et al. Bone morphogenetic protein-9. An autocrine/ paracrine cytokine in the liver. J Biol Chem 2000;275:17937-45.

20 David L, Mallet C, Keramidas M, et al. Bone morphogenetic protein-9 is a circulating vascular quiescence factor. Circ Res 2008;102:914-22.

21 Wu Q, Sun CC, Lin HY, et al. Repulsive guidance molecule (RGM) family proteins exhibit differential binding kinetics for bone morphogenetic proteins (BMPs). PLoS ONE 2012;7:e46307.

22 Song K, Krause C, Shi S, et al. Identification of a key residue mediating bone morphogenetic protein (BMP)-6 resistance to noggin inhibition allows for engineered BMPs with superior agonist activity. J Biol Chem 2010;285: $12169-80$.

23 Mi LZ, Brown CT, Gao Y, et al. Structure of bone morphogenetic protein 9 procomplex. Proc Natl Acad Sci USA 2015;112:3710-15.

24 Kienast $Y$, Jucknischke $U$, Scheiblich $S$, et al. Rapid activation of bone Morphogenic protein 9 by receptor-mediated displacement of pro-domains. J Biol Chem 2016;291:3395-410.

25 Cunha SI, Pardali E, Thorikay M, et al. Genetic and pharmacological targeting of activin receptor-like kinase 1 impairs tumor growth and angiogenesis. J Exp Med 2010;207:85-100.

26 Li Q, Gu X, Weng H, et al. Bone morphogenetic protein-9 induces epithelial to mesenchymal transition in hepatocellular carcinoma cells. Cancer Sci 2013;104:398-408.

27 Wiercinska E, Wickert L, Denecke B, et al. Id1 is a critical mediator in TGF-beta-induced transdifferentiation of rat hepatic stellate cells. Hepatology 2006:43:1032-41

28 Ciuclan L, Ehnert S, Ilkavets I, et al. TGF-beta enhances alcohol dependent hepatocyte damage via down-regulation of alcohol dehydrogenase I. J Hepatol 2010:52:407-16

29 Mogler C, Wieland M, Konig C, et al. Hepatic stellate cell-expressed endosialin balances fibrogenesis and hepatocyte proliferation during liver damage. EMBO Mol Med 2015;7:332-8.

30 Mühlbauer M, Fleck M, Schütz C, et al. PD-L1 is induced in hepatocytes by viral infection and by interferon- $\alpha$ and $-\gamma$ and mediates T cell apoptosis. $J$ Hepatol 2006:45:520-8

31 Dorn C, Weiss TS, Heilmann J, et al. Xanthohumol, a prenylated chalcone derived from hops, inhibits proliferation, migration and interleukin-8 expression of hepatocellular carcinoma cells. Int J Oncol 2010;36:435-41.

32 Huard J, Mueller S, Gilles ED, et al. An integrative model links multiple inputs and signaling pathways to the onset of DNA synthesis in hepatocytes. FEBS $J$ 2012;279:3290-313.

33 Spurgeon SL, Jones RC, Ramakrishnan R. High throughput gene expression measurement with real time PCR in a microfluidic dynamic array. PLOS ONE 2008;3: e1662.

34 Feuer $\mathrm{R}$, Vlaic $\mathrm{S}$, Arlt J, et al. LEMming: a linear error model to normalize parallel Quantitative Real-Time PCR (qPCR) data as an alternative to reference gene based methods. PLOS ONE 2015:10:e0135852.

35 López-De León A, Rojkind M. A simple micromethod for collagen and total protein determination in formalin-fixed paraffin-embedded sections. J Histochem Cytochem 1985;33:737-43.

36 Hawinkels L, Kuiper P, Wiercinska E, et al. Matrix metalloproteinase-14 (MT1-MMP)-mediated endoglin shedding inhibits tumor angiogenesis. Cancer Res 2010;70:4141-50.

37 Hawinkels $L$, de Vinuesa AG, Paauwe $M$, et al. Activin receptor-like kinase 1 ligand trap reduces microvascular density and improves chemotherapy efficiency to various solid tumors. Clin Cancer Res 2016;22:96-106.

38 Hu J, Srivastava K, Wieland M, et al. Endothelial cell-derived angiopoietin-2 controls liver regeneration as a spatiotemporal rheostat. Science 2014;343: 416-19.

39 Dooley S, Delvoux B, Streckert M, et al. Transforming growth factor beta signal transduction in hepatic stellate cells via Smad2/3 phosphorylation, a pathway that is abrogated during in vitro progression to myofibroblasts. TGFbeta signal transduction during transdifferentiation of hepatic stellate cells. FEBS Lett 2001; 502:4-10.

40 Dooley S, Hamzavi J, Ciuclan L, et al. Hepatocyte-specific Smad7 expression attenuates TGF- $\beta$-mediated fibrogenesis and protects against liver damage. Gastroenterology 2008;135:642-59.

41 Godoy P, Hengstler JG, Ilkavets I, et al. Extracellular matrix modulates sensitivity of hepatocytes to fibroblastoid dedifferentiation and transforming growth factor $\beta$-induced apoptosis. Hepatology 2009;49:2031-43.

42 Meyer $\mathrm{C}$, Liebe R, Breitkopf-Heinlein K, et al. Hepatocyte fate upon TGF- $\beta$ challenge is determined by the matrix environment. Differentiation 2015;89:105-16. 
43 Hoehme S, Brulport M, Bauer A, et al. Prediction and validation of cell alignment along microvessels as order principle to restore tissue architecture in liver regeneration. Proc Natl Acad Sci USA 2010;107:10371-6.

44 Sebald W, Nickel J, Zhang JL, et al. Molecular recognition in bone morphogenetic protein (BMP)/receptor interaction. Biol Chem 2004;385:697-710.

45 Herrera B, Dooley S, Breitkopf-Heinlein K. Potential roles of bone morphogenetic protein (BMP)-9 in human liver diseases. Int J Mol Sci 2014;15:5199-220.

46 de Vinuesa AG, Bocci M, Pietras K, et al. Targeting tumour vasculature by inhibiting activin receptor-like kinase (ALK)1 function. Biochem Soc Trans 2016;44:1142-9.

47 Sreekumar V, Aspera-Werz RH, Tendulkar G, et al. BMP9 a possible alternative drug for the recently withdrawn BMP7? New perspectives for (re-)implementation by personalized medicine. Arch Toxicol 2017;91:1353-66.

48 Deleve LD, Wang $X$, Guo Y. Sinusoidal endothelial cells prevent rat stellate cell activation and promote reversion to quiescence. Hepatology 2008;48:920-30.

49 Cornell RP, Liljequist BL, Bartizal KF. Depressed liver regeneration after partial hepatectomy of germ-free, athymic and lipopolysaccharide-resistant mice. Hepatology 1990;11:916-22.
50 Su GL, Wang SC, Aminlari A, et al. Impaired hepatocyte regeneration in toll-like receptor 4 mutant mice. Dig Dis Sci 2004;49:843-9.

51 Mandrekar P, Szabo G. Signalling pathways in alcohol-induced liver inflammation. J Hepatol 2009;50:1258-66

52 Isayama F, Hines IN, Kremer M, et al. LPS signaling enhances hepatic fibrogenesis caused by experimental cholestasis in mice. Am J Physiol Gastrointest Liver Physiol 2006;290:G1318-28.

53 Seki E, De Minicis S, Osterreicher $\mathrm{CH}$, et al. TLR4 enhances TGF-beta signaling and hepatic fibrosis. Nat Med 2007;13:1324-32.

54 Paik YH, Schwabe RF, Bataller R, et al. Toll-like receptor 4 mediates inflammatory signaling by bacterial lipopolysaccharide in human hepatic stellate cells. Hepatology 2003;37:1043-55.

55 Bhunchet E, Fujieda K. Capillarization and venularization of hepatic sinusoids in porcine serum-induced rat liver fibrosis: a mechanism to maintain liver blood flow. Hepatology 1993;18:1450-8.

56 DeLeve LD. Liver sinusoidal endothelial cells in hepatic fibrosis. Hepatology 2015;61:1740-6. 